Flows, Circulations and their Opposites:

\title{
El cuidadómetro fronterizo: Sobrecarga femenina y estrategias de movilidad en la Triple Frontera del Paraná
}

\author{
Menara Guizardi ${ }^{2}$ \\ 'Consejo Nacional de Investigaciones Científicas y Técnicas (CONICET/IDAES/UNSAM), \\ Buenos Aires, Argentina \\ ${ }^{2}$ Universidad de Tarapacá (UTA), Arica, Chile
}

\section{Resumen}

El artículo aborda la relación entre las sobrecargas de los cuidados y las estrategias de movilidad transfronteriza femeninas en la Triple Frontera del Paraná. Se muestra cómo las asimetrías estatales entre los tres países colindantes (Argentina, Brasil y Paraguay) generan diferencias de acceso a derechos básicos, particularmente, a la atención sanitaria. Partiré contextualizando la Triple Frontera, ofreciendo una síntesis de las experiencias/ problemáticas femeninas en estos territorios. Luego, revisaré los debates teóricos sobre cuidados, fronteras y género en territorios transfronterizos. Los apartados cuatro, cinco y seis recuperan mis diálogos con tres mujeres, conduciendo a reflexiones sobre cómo ellas elaboran un "cuidadómetro": basando sus estrategias de movilidad transfronterizas en las mediciones de las potencialidades del cuidado recibido y entregado en cada lado de las fronteras.

Palabras-clave: cuidados; movilidades fronterizas; género; etnografía; Triple Frontera del Paraná. 


\section{O Cuidadômetro fronteiriço: Sobrecarga feminina e estratégicas de mobilidade na Tríplice Fronteira do Paraná}

\section{Resumo}

O artigo aborda a relação entre as sobrecargas dos cuidados e aas estratégias de mobilidade transfronteiriças femininas na Tríplice-fronteira do Paraná. Mostrarei como as assimetrias estatais entre os três países contíguos (Argentina, Brasil, Paraguai) geram diferenças substantivas de acesso a direitos básicos como a atenção sanitária. Iniciarei contextualizando a tríplice-fronteira, oferecendo uma síntese das experiências/ problemáticas femininas nestes territórios. Logo, revisarei os debates teóricos sobre cuidados, fronteiras e gênero nos territórios fronteiriços. As seções quatro, cinco e seis recuperam meus diálogos com três mulheres, conduzindo a reflexões sobre como elas elaboram um "cuidadômetro": amparam suas estratégias de mobilidade transfronteiriças nas medições das potencialidades de cuidado recebido e entregue em cada lado das fronteiras.

Palavras-chave: cuidados, mobilidades fronteiriças, gênero, etnografia, Tríplice-fronteira do Paraná. 


\title{
El cuidadómetro fronterizo: Sobrecarga femenina y estrategias de movilidad en la Triple Frontera del Paraná
}

\author{
Menara Guizardi
}

\section{Introducción: las mujeres y el cuidadómetro fronterizo'}

Desde los 199os, los estudios socio-antropológicos vienen demostrando que las responsabilidades de los cuidados familiares y comunitarios influencian centralmente las decisiones de muchas mujeres latinoamericanas sobre cómo organizar y sostener experiencias migratorias (Aranda, 2003; Bryceson \& Vuorela, 2002; Herrera, 2012). Este debate ha visibilizado la relación entre migraciones, asimetrías de género y cuidados, estableciendo que el cruce de fronteras está vinculado con la sobrecarga (re)productiva femenina (Gonzálvez, 2016).

Desde los escritos fundacionales de Anzaldúa (1987), se vienen observando estas problemáticas en ciudades fronterizas entre México y Estados Unidos (EEUU) (Lugo, 199o; Molina, 1985; Monárrez, 2013; Woo, 2004). Pero esta preocupación es aún incipiente en los estudios sobre las localidades transfronterizas sudamericanas. Subsanando esta falta, Viteri et al. (2017:124) comparan diversas fronteras de este continente. Observan que la sobrecarga y los mandatos de género vinculados a la obligación de cuidar exponen las mujeres a diversas formas de violencia fronterizas. Por otra parte, estudios sobre las movilidades en las fronteras entre Chile, Perú y Bolivia muestran que los cuidados constituyen, simultáneamente, el impulso a formas específicas de agencia femenina (Guizardi et al., 2019). Dicha agencia estaría organizada a partir de estrategias de desplazamiento con las cuales las mujeres buscan obtener beneficios, controlando los ritmos y lógicas del cruce fronterizo (Renoldi, 2013; 2014).

Con la atención puesta en esta dialéctica - y considerando que el cuidado oscila contradictoriamente entre la producción y la ruptura de desigualdades y violencias de género - abordaré la relación entre las responsabilidades reproductivas y las estrategias de movilidad transfronteriza de mujeres que habitan en la Triple Frontera del río Paraná (entre Argentina, Brasil y Paraguay). A través de sus experiencias, mostraré cómo las asimetrías de configuración urbana entre los tres países colindantes generan diferencias sustantivas de acceso a derechos básicos (particularmente, la atención sanitaria). La sobrecarga femenina en los cuidados impulsa a las mujeres a comparar y computar estas diferencias para trazar sus trayectorias de movilidad. Las contribuciones del presente trabajo apuntan a tres objetivos específicos, que buscan complementar y expandir los debates sobre migración y movilidad transfronteriza.

En primer lugar, abordan un tema poco discutido en los estudios precedentes en la Triple Frontera del Paraná: busca visibilizar y comprender, a partir de una perspectiva de género, el papel de las sobrecargas femeninas del cuidado familiar, y su importancia como factor que impulsa a las mujeres a moverse a través de las fronteras en esta región. Los trabajos desarrollados en los territorios del trifinio han investigado diversos elementos cruciales para comprender las dinámicas poblacionales transfronterizas. Por un lado, han averiguado los déficits de acceso al Sistema de Protección Social (asistencia sanitaria, médica, educacional y de acceso a derechos sociales básicos) por parte de la población transfronteriza entre Paraguay y Brasil

\footnotetext{
$1 \quad$ Agradezco los financiamientos de la Agencia Nacional de Investigación y Desarrollo de Chile, a través del proyecto Fondecyt 1190056 y del Fondo para Investigación Científica y Tecnológica de Argentina, a través del proyecto PICT 201-01022016.
} 
(Albuquerque, 2012). Por otro, han indagado sobre las asimétricas disputas de poder que estas poblaciones protagonizan (y en ocasiones, sufren) en sus dinámicas de desplazamiento (Albuquerque, 2008) y en el asentamiento en territorios productivos agrícolas (Fogel, 2008).

Además, han introducido una perspectiva de género, al tratar de estas movilidades transfronterizas. Profit (2015), por ejemplo, estudió la desigualdad social, discriminación y abusos laborales sufridos por mujeres paraguayas empleadas en el lado brasileño de la frontera, en su inserción como trabajadoras domésticas y del comercio. Cardin (2012) observó la especificidad del trabajo femenino en el contrabando y las representaciones sociales de las mujeres en la zona fronteriza (Lima \& Cardin, 2019). A su vez, Renoldi (2013) se ocupó de la inserción femenina en el comercio, turismo y servicios domésticos del lado argentino; mientras, los estudios de Barvinsk (2014), de la Organización Internacional del Trabajo (OIT, 2002) y de Zsögön (2013) abordaron la trata de mujeres y menores para la prostitución.

Las contribuciones de estos estudios constituyen un punto de partida de la presente investigación, dado que permiten tejer un panorama de las realidades femeninas en la zona. Pero mi apuesta aquí es la de abordar más centralmente el papel crucial que el cuidado tiene en la definición de las estrategias femeninas de movilidad. En este sentido, se expanden las investigaciones previas, tematizando específicamente el cuidado que las mujeres están compelidas a desarrollar en su propio hogar, en su propia familia (y no en el mercado laboral transfronterizo), como elementos cruciales de la experiencia femenina de desplazamiento.

En segundo lugar, el presente trabajo busca expandir también los debates sobre la relación entre los cuidados y las migraciones. En diferentes regiones del mundo, los estudios migratorios y de género vienen planteando interrogantes fundamentales sobre el cuidado (Gonzálvez, 2016; Herrera, 2012; Hochschild, 2001; Mattingly, 2001; Pisani \& Yoskowitz, 2002). Este es un concepto polisémico, que responde a las diversas expresiones cotidianas en que esta práctica puede manifestarse; discusión que retomaré con más detalle en el segundo apartado del texto. No obstante, cabe adelantar que la categoría cuidado, tal como la utilizo en este trabajo, refiere a actividades asignadas cultural e históricamente a las mujeres, que hacen posibles la reproducción de la vida (Gonzálvez, 2016).

Los estudios de la migración transnacional de larga distancia - desarrollados con mujeres migrantes desde localidades del sur global hacia las grandes metrópolis del norte global - han demostrado que muchos de los acuerdos y arreglos de cuidado que sostienen los hogares desde la globalización se reproducen en un contexto transnacional/transfronterizo, a través del trabajo coordinado de diversas mujeres, desencadenando lo que Hochschild (2001) denominó cadenas globales de cuidado. Dichas investigaciones apuntan a que la configuración de una desigualdad de género en la distribución de los trabajos del cuidado y de reproducción social de las familias, en los distintos lados de las fronteras nacionales, articula formas específicas de inserción y subordinación femeninas (Sassen, 2003:43). Estas formas, simultáneamente, conectan a las mujeres que migran o que se desplazan a través de las fronteras en una cadena de transferencia de las sobrecargas del cuidado (Mattingly, 2001:371; Pisani \& Yoskowitz, 2002:578). Estos estudios dejan al descubierto, entonces, que la desigualdad - entre la obligación de cuidar y la falta de apoyos a los que derivar estas responsabilidades - empuja a las mujeres a complejas cadenas de precarización laboral y constituye, asimismo, una desprotección, dado que la mayoría de ellas no acceden a recibir cuidados (Woo, 2004:54).

El presente trabajo expande estas reflexiones, indagando sobre las cadenas de cuidado que se entretejen en circuitos de desplazamiento - o migratorios - de corta distancia, es decir, de carácter transfronterizo. Se trata, entonces, de una búsqueda por entender cómo estas cadenas globales de cuidado operan en estos espacios donde el desplazamiento femenino es tanto más intenso, debido no solamente a la cercanía espacial entre el país de origen y el país hacia el cual se dirigen (a veces diariamente) las mujeres fronterizas, sino por la propia lógica de interconexión económica, social, cultural y política de los espacios transfronterizos. Como bien ha definido Stephen (2012:456-463), dichos espacios presentan una intensidad circulatoria elevada, particular, 
que excede las formas de conexión entre territorios migratorios transnacionales de larga distancia. Por lo mismo, las cadenas de cuidado feminizadas en las zonas fronterizas constituyen dinámicas sui generis, que difieren de aquellas desarrolladas por mujeres que migran internacionalmente hacia localidades distantes de sus localidades de origen. Si bien en la Triple Frontera del Paraná se ha estudiado la dimensión laboral de estas cadenas - es decir, la inserción laboral de las mujeres como cuidadoras y trabajadoras domésticas (Profit, 2015; Renoldi, 2013) -, aún no se ha indagado la dimensión "doméstica" de los cuidados como elemento estructurado desde la vida familiar femenina (o, al menos, no en su vinculación con las movilidades espaciales).

En tercer lugar, el presente estudio también contribuye a expandir algunas de las definiciones más clásicas de los estudios migratorios internacionales. Particularmente una afirmación, repetida por diversos autores, según la cual se asume que los sectores sociales más pobres de cada sociedad no migran, puesto que la migración "es una empresa y requiere generalmente de ciertos ahorros y redes sociales" (Grimson, 2011:36). Según estos argumentos, dichos sectores más empobrecidos "muchas veces están condenados a no poder ni siquiera migrar" (Grimson, 2011:36). A través de los datos etnográficos recopilados, se mostrará cómo esta asunción, si bien puede ser aplicada a las migraciones transnacionales de larga distancia, no se verifica en las movilidades transfronterizas femeninas. Mostraré, asimismo, que la movilidad femenina transfronteriza es, precisamente, una salida para aquellas mujeres que, atravesando situaciones de vulnerabilidad, utilizan el cruce de fronteras como una estrategia económica para sobrellevar las sobrecargas del cuidado y proyectar, en algunos casos, una acumulación de capital para una migración de mediana o larga distancia.

Los tres ejes referidos están articulados por un hallazgo etnográfico: para las mujeres que entrevisté en la Triple Frontera del Paraná, las decisiones sobre en qué momento y hacia dónde desplazarse dependen, centralmente, de sus cálculos sobre la cantidad y calidad de cuidados que podrán ofrecer a su núcleo familiar y a sí mismas. Los cálculos sobre el cuidado atraviesan todas las esferas de preocupación de estas mujeres y moldean, como veremos en los apartados etnográficos, sus posicionamientos políticos, sus vínculos laborales, sus relaciones interpersonales, sus lógicas de ahorro, sus estrategias económicas. Conversando sobre estos hallazgos, Alejandro Grimson ${ }^{2}$ me sugirió el término "cuidadómetro" para explicitar este sistema dinámico de medición del cuidado que las mujeres establecen a la hora de decidir cómo, hacia dónde y con quién moverse a través de las fronteras.

Todos y cada uno de los apartados etnográficos de este artículo apuntan a mostrar las múltiples manifestaciones de este "cuidadómetro" en las vidas de las mujeres entrevistadas. Esto permite retratar, además, cómo las políticas del cuidado en la Triple Frontera (particularmente, en lo que concierne al sistema sanitario) están atravesadas por cuestiones regionales e interregionales, no sólo entre los países, sino también entre las diversas provincias, estados o departamentos de cada país ${ }^{3}$ Estas asimetrías y desigualdades (inter o intra) territoriales impactan los criterios de cuidado de las mujeres, conformando, por lo mismo, uno de los elementos centrales en los cómputos del "cuidadómetro".

Las informaciones cualitativas que analizaré a lo largo del texto derivan de una etnografía que vengo realizando desde $2017 .{ }^{4}$ Las narraciones recuperadas describen los tres primeros encuentros con mujeres fronterizas, mantenidos en el viaje que realicé junto de Eleonora López ${ }^{5}$ entre el 14 de julio y el 2 de agosto de 2019. El primero de ellos, ocurrido un domingo, fue con María, una mujer paraguaya a quien conocí en el

\footnotetext{
2 Es investigador del Consejo Nacional de Investigaciones Científicas y Técnicas de Argentina (CONICET), fue mi director postdoctoral y el interlocutor con quien dialogué sobre mis experiencias etnográficas en las fronteras sudamericanas.

3 Cada país que confluye en el trifinio denomina de manera particular las unidades administrativas de sus repúblicas. Brasil está dividido en "estados”; Argentina en "provincias"; y Paraguay, en "departamentos".

4 Comprendo la etnografía como la observación sistemática de los contextos sociales con la finalidad de participar de ellos, registrarlos, analizarlos y construir relatos. La perspectiva etnográfica busca la interacción crítica entre sujetos de estudio e investigadores: es un enfoque, un método y un ejercicio de relato intersubjetivo (Guber 2001:12).

5 Eleonora López es doctoranda en sociología y es asistente de investigación en el equipo del proyecto Fondecyt 1190056 (ver nota de pie de página $\mathrm{n}^{\circ}$ 1)
} 
bus, viajando desde Buenos Aires (Argentina) a la Triple Frontera. El segundo, el lunes, con Amarena, una joven argentina que trabaja en la terminal de buses de Puerto Iguazú (Argentina). El tercero, el martes, con Bernadette: una brasileña que vivió tres décadas en Paraguay, a quien conocí en Foz de Iguazú (Brasil). ${ }^{6}$ A través de sus narraciones, veremos cómo el cuidado impacta en la experiencia femenina del espacio, influenciando las estrategias de movilidad que estas mujeres desarrollan.

En el segundo apartado, contextualizaré el territorio de la Triple Frontera, ofreciendo una síntesis de experiencias/problemáticas femeninas que estudios previos han observado en las ciudades fronterizas. El tercer apartado discute el marco teórico que fundamenta el artículo: los debates sobre cuidados, fronteras y género en las movilidades transnacionales/transfronterizas. Los apartados cuatro, cinco y seis recuperan mis diálogos con María, Amarena y Bernadette. Finalizo con reflexiones sobre la relación entre cuidados y estrategias de movilidad fronteriza y su configuración, a partir del "cuidadómetro".

\section{El contexto}

La Triple Frontera está situada entre los ríos Paraná e Iguazú, territorio ancestral de los grupos guaraníes. Desde el término de la Guerra del Paraguay (1864-1870)7, esta área estuvo semi-poblada y sólo empezó a transformarse en una zona estratégica para Sudamérica entre los 1960s y 1980s (Albuquerque, 2012). Entonces, se pactó y se dio inicio a la construcción de las centrales hidroeléctricas de Itaipú (1971-1985), entre Brasil y Paraguay, y de Yacyretá (1983-2011), entre Paraguay y Argentina (Renoldi, 2013:125). Ambas fueron impulsadas por gobiernos militares de los tres países, a partir de proyectos desarrollistas con impactos sociales sustantivos (Lins Ribeiro, 1999), ${ }^{8}$ para los cuales los gobiernos no se prepararon suficientemente (Renoldi, 2013). La dinamización económica impulsada por las hidroeléctricas provocó un sostenido crecimiento demográfico en la Triple Frontera (Lynn, 2008); pese a ello, el lado argentino permanecería menos poblado por una decisión de los militares en la dictadura de Videla (1976-1981) de no disputar las fronteras con Brasil (Grimson, 2002). Fue a partir de allí que las tres ciudades que colindan en esta Triple Frontera empezaron a ganar alguna notoriedad.

Foz de Iguazú, del lado brasileño, es la más antigua de las tres. Fue fundada en el siglo XIX como un asentamiento militar de pequeñas dimensiones (Renoldi, 2013). Su crecimiento poblacional y económico empezó a acelerarse en 1965, con la construcción del "Puente de la Amistad", que la conecta con la paraguaya Ciudad del Este (Lynn, 2008). En el último censo brasileño (en 2010), Foz contabilizaba 256.081 habitantes (Albuquerque, 2012:191).

Ciudad del Este, del lado paraguayo, fue fundada en 1957 a partir de un decreto presidencial (Lynn, 2008), y con la finalidad de servir de enganche territorial con Foz, a través del puente (inaugurado 6 años después de la fundación de la ciudad). En los 1980s, se convirtió en Zona Franca, transformándose en un gran centro de comercio (i)lícito internacional de diversos productos. Esto activó una economía de grandes dimensiones con Foz y con Puerto Iguazú. La zona franca consolidó un importante nicho laboral femenino:

\footnotetext{
6 Siguiendo a los protocolos éticos de la investigación, las personas mencionadas tuvieron sus identidades protegidas por seudónimos.

7 El conflicto enfrentó la Triple Alianza (Brasil, Argentina y Uruguay, con apoyo británico) al ejército paraguayo, y se desencadenó por contiendas económicas y de determinación de los territorios, soberanías y fronteras (Reber, 1988). La victoria de la Alianza alimentó, con simbolismos militares y raciales, las nociones de diferencias étnico-identitarias entre Brasil y Argentina, en contraposición a Paraguay. Brasileños y argentinos, cada uno a su modo, proyectaron su victoria como prueba de una supuesta superioridad racial, moral y civilizatoria. Estos imaginarios siguen vigentes, tanto en Brasil (Souchaud, 2011) como en Argentina (Grimson, 2012).

8 Por ejemplo, dotaron el área de una infraestructura de transporte fluvial y terrestre de las más articuladas del Cono Sur americano (Lynn 2008).
} 
el comercio legal y el contrabando "hormiga" (a pequeña escala) (Cardin, 2012). ${ }^{9}$ Es la ciudad con el mayor crecimiento demográfico en la Triple Frontera. En el último censo paraguayo (en 2012), tenía 312.652 habitantes, muchos de origen brasileño (Souchaud, 2011).

Puerto Iguazú, del lado argentino, fue fundada en 1902 y es parte de la provincia de Misiones (Renoldi, 2013). La ciudad contaba con una población total de 42.849 personas según el censo de 2010 (Dachary \& Arnaiz, 2012). Su principal actividad es el turismo (dirigido a las Cataratas del Iguazú) y está vinculada a Foz a través del “Puente de la Fraternidad”, inaugurado en 1985 (Giménez, 2011:8). En Puerto Iguazú, los principales nichos de inserción laboral femenina son la venta de productos artesanales turísticos y el comercio transfronterizo. Las mujeres que trabajan en esta última actividad se están reorientando hacia los trabajos de cuidados y servicios domésticos, debido a la crisis del circuito comercial (Renoldi, 2013:131).

Pese al crecimiento de la zona, entre los 1970s y 1980s, es recién en los 199os que pasa a ser efectivamente entendida como una Triple Frontera (Giménez, 2011; Rabossi, 2004), transformación potenciada por la firma del Tratado del Mercado Común del Sur (Mercosur), en 1991. Actualmente, las tres ciudades configuran la zona transfronteriza con mayor flujo humano (Albuquerque, 2008), de mercancías (Sausi \& Oddone, 2010), de turismo (Cury \& Fraga, 2013) y de actividades ilícitas de Sudamérica (Cardin, 2012:208), especialmente, tráfico de drogas y mercancías (Cardin, 2012), crimen organizado (Costa \& Schulmeister, 2007) y trata -de mujeres y menores- con fines sexuales (OIT, 2002; Zsögön, 2013).

Según Cardin (2012) y Renoldi (2013), el peculiar dinamismo de esta Triple Frontera se caracteriza por unos circuitos de movilidad y de relaciones (económicas, sociales y culturales) en las que legalidad e ilegalidad, pertenencia y desarraigo, no se constituyen como pares antagónicos. Por ello, resulta difícil pensar estas tres ciudades por separado. Ellas se interpelan fuertemente en términos económicos, políticos y culturales. Conforman, entonces, una conurbación tri-fronteriza con más de 60o.ooo personas (Renoldi, 2014:2). La vida cotidiana de quienes allí habitan conlleva el constante cruce entre fronteras, entre ciudades. Pero esta movilidad se encuentra mucho más distendida entre el lado brasileño y el paraguayo: los habitantes refieren al límite entre estos países como una "frontera abierta", dada la laxitud fiscalizadora de las autoridades. Esto no implica que los cruces entre Brasil y Argentina, y entre esta y Paraguay, no sean intensos. Son - esto sí - mucho más controlados por las autoridades argentinas, mereciendo de parte de los habitantes la denominación de "frontera cerrada".

Todas estas configuraciones hacen de la Triple Frontera un espacio particular para las mujeres. Primero, porque se trata de uno de los principales territorios de acción de las redes transnacionales de trata de mujeres con fines sexuales de Sudamérica (Barvinsk, 2014; OIT, 2002; Zsögön, 2013). Los diagnósticos apuntan a que el fenómeno está profundamente articulado con los circuitos turísticos y comerciales fronterizos (OIT 2002:16) ${ }^{10}$. En segundo lugar, las mujeres están expuestas a la interseccionalidad de diferentes formas de discriminación y marginación social (de clase, nacional, étnica/racial). Estas interseccionalidades tienen consecuencias profundas en la organización económica y política del territorio. Por ejemplo, las poblaciones indígenas, afro y mestizas tienden a sufrir procesos más violentos de expropiación de áreas agrícolas en los tres países (Fogel, 2008). La ruptura de la unidad productiva familiar y la ausencia de salidas laborales masculinas empujan a las mujeres a responsabilizarse, productiva y reproductivamente, de las familias. Así, ellas, especialmente si son negras, indígenas o mestizas, acarrean más vulneraciones en los tres lados de la frontera. Por último, las movilidades transfronterizas están interrelacionadas con las transformaciones de los lazos familiares, roles de género, y sobrecarga (re)productiva femenina (Ribeiro \& Geusina, 2008; Profit, 2015). Es sobre este último punto que detendremos nuestra atención.

\footnotetext{
9 Este comercio vive, actualmente, un ciclo de desaceleración que detonó procesos de reordenamiento de la economía comercial a pequeña escala en Ciudad del Este (Giménez 2011), afectando especialmente a los nichos de actividad femeninos (Renoldi 2013).

10 Según Seaman (2012:31) la trata humana sería parte del contexto polifacético de institucionalidad del contrabando y del tráfico transfronterizo. Estas interacciones liminales exponen a las mujeres a redes de trata, aunque generalmente sean cooptadas por un familiar cercano (Barvinsk, 2014:75).
} 


\section{Debates teóricos}

Desde los 199os, las perspectivas antropológicas sobre la movilidad transnacional/transfronteriza vienen considerando que las relaciones de género - sus asimetrías y jerarquías - constituyen un elemento central de las experiencias femeninas: al desplazarse, las mujeres (re)producen y rompen (contradictoriamente) las experiencias de subalternidad y dominación. Lo anterior se observaría en las migraciones transnacionales (de larga o corta distancia) y en las movilidades transfronterizas (Guizardi, González \& Stefoni, 2018:40-44). Este artículo dialoga con esos debates, y propone observar su operacionalización en las trayectorias femeninas que atraviesan la Triple Frontera del Paraná. Se busca mostrar cómo los cuidados son centrales para las mujeres en sus estrategias de desplazamiento fronterizo. Pero, ¿a qué me refiero cuando hablo de cuidados?

El concepto alude a toda una diversidad de prácticas que pueden o no ser remuneradas; estar o no reguladas por un contrato laboral; desarrollarse en el espacio doméstico o en el público y que, además, pueden cruzar fronteras nacionales y establecerse entre países distintos (Gonzálvez, 2016:45). Según Glenn (2010:5), involucran el cuidado directo de las personas (bañarlas, alimentarlas, limpiarlas, vestirlas); el cuidado emocional (conversar, consolar, dialogar, atender); los servicios indispensables para las dos anteriores (comprar alimentos, ropas, pagar cuentas, comprar remedios) y el mantenimiento de los espacios donde se vive (limpieza, arreglos) (Gonzálvez, 2016). Otro cuidado consiste, además, en fomentar los vínculos relacionales, familiares y comunitarios, lo que la antropología feminista denomina "trabajo de parentesco" (Gonzálvez et al., 2019). Todas estas actividades son centrales para la reproducción social.

El concepto de reproducción social deviene de los debates marxistas que fueron reinterpretados por el feminismo, a partir de la crítica al concepto que Simone de Beauvoir ofrece en el tercer capítulo de su libro "El segundo Sexo" (Beauvoir, 2018 [1949]). Si bien esta crítica se hace presente en los discursos y argumentos de los movimientos sociales feministas desde fines del siglo XIX (Beauvoir, 2018:24-25), es solamente en los 1970s que ella adentrará los debates de las feministas en las ciencias sociales y, en particular, en la antropología (Lamas, 1986:174). ${ }^{11}$ Esto provoca un redimensionamiento del debate sobre reproducción social (Ferguson, 2008:43).

En el argumento marxista, el modo capitalista de producción, para existir, debe no solamente producir sus condiciones de existencia, sino también su continuidad histórica (Laslett \& Brenner, 1989). Así, la producción del capitalismo implicaría la reproducción de los mecanismos que fomentan la mantención de las divisiones, inequidades y asimetrías entre clases, y entre los bloques internos de estas clases (Bourdieu, 2011). Extrapolando el debate de Althusser (1988 [1970]) - para quien ciertas instituciones sociales como la familia, el Estado, la Iglesia y la escuela constituirían elementos centrales para el mantenimiento de estas estrategias de reproducción de la desigualdad - el argumento feminista en las ciencias sociales cuestionará la subalternización de género que subyace a estas mismas estrategias (Ferguson, 2008). Denunciará, así que la continuidad del modo productivo descansa sobre los hombros de las mujeres, quienes se encargan de la mayor parte del esfuerzo de "reproducir" nuevas generaciones. Esto desencadena desventajas cruciales para ellas, que son magnificadas en el curso de sus vidas (Gonzálvez et al., 2019).

Considerando estos aspectos, los estudios sociales sobre los cuidados se vienen articulando a partir de una perspectiva transversal de género. Esta perspectiva asume un claro posicionamiento político. Se plantea el imperativo de desnaturalizar la sobrecarga femenina del cuidado, estableciendo que las democracias contemporáneas deben garantizar los cuidados por medio de arreglos institucionales y presupuestarios; que este debe ser normado y obtener apoyo estatal (Daly \& Lewis, 2000).

11 En la antropología anglófona, son considerados textos fundacionales de este debate sobre reproducción social los volúmenes editados por Rosaldo y Lamphere (1974), y por Rapp (1975). 
La relación de estas reflexiones con las movilidades transfronterizas comenzó a ganar centralidad analítica en los 1980s, cuando la frontera México/EEUU emergió como espacio privilegiado para investigar la condensación de las relaciones de género. A partir de estos estudios, las regiones fronterizas empezaron a ser definidas como espacios de negociación simbólica, de procesos políticos e identidades culturales (Garduño, 2003:15); la de género, entre ellas (Álvarez, 1995:450). Es en este momento que surgen estudios preocupados por la experiencia transfronteriza de las mujeres.

La obra de Anzaldúa (1987) es considerada fundacional en este campo crítico. Sus escritos interpelan la historia social y política del espacio, que es atravesada con las historias personales y familiares de la autora. Esta intersubjetividad crítica le facilita "abrir" la frontera, a partir de su presencia en ella, situando su cuerpo, su experiencia del género y de la violencia como facilitadores de una historiografía donde el sujeto subalterno se convierte en el centro de una comprensión del espacio. Desde entonces, las aportaciones de investigadoras latinoamericanas en esta frontera constituyen una contribución central a la superación de la invisibilización de discriminaciones étnicas/raciales, en el marco de las reflexiones sobre los territorios fronterizos (Lugo, 1990; Monárrez, 2013; Woo, 2004).

Entre las varias conclusiones de estos estudios, tres son fundamentales. La primera alude a que la vulnerabilidad laboral de las mujeres fronterizas se extiende ( $\mathrm{y}$ frecuentemente se origina) en el ámbito doméstico: en sus relaciones con sus progenitores, parejas y miembros masculinos de sus familias (Molina, 1985:33). A partir de la instauración de las economías globalizadas y flexibilizadoras del trabajo en la frontera México/EEUU - que emplean a más mujeres, por considerarlas más explotables - el desempleo masculino provocó que los hombres se sintieran desplazados de su rol de proveedores económicos. Esto derivó en brotes de violencia de género (Molina, 1985:35-36). La segunda: las mujeres transfronterizas indocumentadas enfrentan una mayor cantidad de violaciones de sus derechos humanos en el cruce de fronteras (Woo, 2004:74). Así, la condición de género contribuye a la configuración de un encadenamiento de violencias, que se magnifican a lo largo de todo el itinerario hasta la frontera. La tercera: a inicios del siglo XXI, centenas de mujeres que trabajaban en las maquilas de Ciudad Juárez (México) fueron asesinadas brutalmente. Entre 1994 y 2004, alrededor 400 mujeres perdieron la vida en estos feminicidios (Arriola, 2006:603). Pese a la repercusión pública que alcanzaron estos casos, los asesinos siguieron impunes por muchos años (Monárrez, 2013). Los trabajos desarrollados sobre este fenómeno argumentan que las mujeres poseen un rol dialéctico en los espacios fronterizos: encarnan, histórica y culturalmente, la sumisión específica de sus contextos cotidianos y, simultáneamente, son agentes activos de resistencia (personal y comunitaria) (Morales \& Bejarano, 2009).

Estos estudios permiten establecer una interrelación nefasta entre la aplicación de reformas neoliberalizantes en los mercados laborales fronterizos, la explotación productiva femenina, la sobrecarga reproductiva de las mujeres, y el ciclo de intensificación de las violencias de género en la frontera México/ EEUU. En adelante, siguiendo estas interrelaciones en la vida de tres mujeres en la Triple Frontera del Paraná, me propongo comprender el lugar de los cuidados en la producción de las localidades fronterizas y de las movilidades femeninas.

\section{María}

Eleonora y yo saldríamos de Buenos Aires el domingo 14 de julio de 2019 a las 13:30 hs. Llegamos a la estación de buses de Retiro con antelación, pero nuestro bus venía con 30 minutos de atraso. Apenas lo estacionó el chofer, entregamos nuestras valijas y ocupamos nuestros asientos en el piso inferior (el bus tiene dos pisos). El piso inferior estaba conformado por un conjunto de pares de asientos (posicionado sobre el lado derecho del vehículo, si miramos desde la entrada hacia la parte trasera), y un conjunto de asientos unitarios del lado izquierdo. Un pasillo separa, a lo largo del bus, ambos conjuntos. En los dos primeros asientos de a par, viajaban 
una señora y su hijo -María y Ulises, descubriríamos después-. Un señor viajaba en la silla unitaria, separado de ellos por el pasillo. Detrás de María y su hijo, iba una pareja de jóvenes (de unos 25 años). Eleonora y yo estábamos inmediatamente detrás de ellos. En el último asiento unitario, del lado izquierdo, una fila detrás nuestro, se encontraba un hombre que leía novelas todo el tiempo.

En su trayecto hacia Puerto Iguazú, el bus va parando en diversas ciudades argentinas que bordean el río Uruguay: atraviesa una parte de la provincia de Buenos Aires hasta la provincia de Entre Ríos. Tras cruzar a esta última, avanza sobre la provincia de Corrientes y, luego, sobre la de Misiones, bordeando y/o cruzando los afluentes del río Paraná. Es un viaje lento, de más de 20 horas. La lentitud no se debe a la distancia: los $1257 \mathrm{~km}$ que separan la capital argentina de Puerto Iguazú podrían realizarse en 16 horas en un automóvil particular. Pero el bus va parando en diversos puntos del trayecto, en aquellos pueblos coloniales que conformaron, en algún momento de su historia, territorios guaraníes. En la ciudad de Gualeguaychú, Entre Ríos, a orillas del río Uruguay, paramos por unos minutos más, para que los/las pasajeros/as pudiéramos usar los baños y comprar comida. Con Eleonora, aprovechábamos cada parada para conversar con los/las demás pasajeros/as, y observar los flujos de cada estación. En esta quinta parada, observamos que María aún no había bajado del bus ni una vez. Casi todos los pasajeros desocupábamos el bus; pero ella permaneció sentada, cuidando a su hijo, que tenía problemas de movilidad. Nos apresuramos a comprar nuestro café y usar el baño. Volvimos al colectivo para preguntarle si necesitaba que le compráramos comida o que la ayudáramos a llevar a su hijo al baño.

Al escuchar nuestro ofrecimiento, María hizo una expresión de sorpresa y nos agradeció sonriendo: no era necesario, su marido ya había bajado a comprar. Miré, entonces, al asiento unitario a su lado, y vi que estaba vacío. Fue así como nos enteramos de que el señor de la primera fila era su marido y el padre del niño. La revelación nos causó sorpresa. Desde Buenos Aires a Gualeguaychú estuvimos dos horas en el bus; y el hombre no había proferido palabra, ni a María ni al pequeño. María, por otro lado, pasó todo ese tiempo atendiendo al niño, que requería asistencia constante. Conversaba con él, le secaba la saliva, le daba de beber, jugaba con él; todo con mucha paciencia y cariño. La ausencia de la participación del hombre en estos cuidados - y en el diálogo con madre e hijo - nos hizo suponer inicialmente que María no conocía al hombre.

La escena descripta constituye una condensación de las desigualdades que se verifican en la responsabilidad de los cuidados, entre las figuras progenitoras femenina y masculina. Y la expresión de dicha desigualdad, en un acto rutinario - como ocupar un lugar en un medio de transporte público - era explícita al punto de establecer, para observadoras externas (Eleonora y yo), la apreciación de que no había entre aquella figura masculina y la femenina con el hijo un lazo parental o forma de vínculo alguna. No por casualidad la madre viajaba en el asiento doble, acompañando de cerca a su hijo, mientras el padre del niño ocupaba un asiento individual. Esta localización equivalía a la disposición espacial de una desigualdad en la responsabilidad de cuidado. Era, asimismo, la condensación gráfica de la sobrecarga femenina: ellos nunca se turnaron en sus asientos. El hombre durmió cómodamente todo el viaje, mientras María cuidaba al niño.

De pie, con mi café en las manos, me puse a charlar con María. Eleonora me acompañó. Empezamos una animada conversación. Le comenté que el billete del bus decía que llegaríamos a las 7:0o hs. del día siguiente a Puerto Iguazú e indagué si era posible que esto sucediera. Me dijo que no: llegaríamos después de las 10:oo hs. Nos reímos con la constatación: nos venden un pasaje que indica un horario de llegada que no se cumple. María dijo que hacía siempre este viaje y que raras veces se llegaba a destino antes de las 11:0o hs. El tránsito entre Buenos Aires y la Triple Frontera del Paraná era parte de su vida: lo había hecho muchas veces y lo hacía siempre.

Mientras nos reíamos, entró al ómnibus su marido, que logró escuchar parte de la conversación y coincidió que los horarios consignados en los pasajes no eran creíbles. María nos presentó a su marido, quien nos saludó cordialmente mientras regresaba a su asiento. Mientras el bus no se movía, seguimos conversando. María nos contó, entonces, que era paraguaya, y que desde hacía diez años vivía en Buenos Aires. Provenía de un pequeño 
pueblo rural, al norte de Ciudad del Este, cerca del límite entre los departamentos paraguayos de Alto Paraná (cuya capital es Ciudad del Este) y de Canindeyú. La principal actividad económica de su localidad de origen es el cultivo de algodón, maíz y, en los últimos años, soja.

Tenía cinco hermanos/as en total. Pero ninguno/a permaneció en la localidad de origen: todos/as emigraron a Ciudad del Este para trabajar. ${ }^{12}$ Desde que la soja tomara los campos, contó, migrar a las ciudades era la única forma de conseguir trabajo. Desde Ciudad del Este, los migrantes rurales como ella establecen lazos y ahorran plata para migrar a Buenos Aires. No suelen ir a la ciudad argentina en la Triple Frontera - Puerto Iguazú - a trabajar, decía, porque es "muy chica, con pocas oportunidades".

María, su marido y el hijo de ambos viajaban para pasar las vacaciones de invierno en la casa de una de las hermanas de ella. Se tomarían unos días para ir al campo a visitar la casa de sus padres, que se negaban a migrar a la ciudad: seguían en su pequeña chacra, ayudados por las remesas de los/las hijos/as. Nos contó que, cuando llegaran a Puerto Iguazú, los recibiría otra de sus hermanas, que venía a buscarla para asistirla en los cuidados del niño mientras viajaban. Así, con la asistencia familiar, tomarían la balsa que lleva desde Puerto Iguazú a Puerto Franco (en Paraguay) y, de allí viajarían en el auto del marido de la hermana los $13 \mathrm{~km}$. hasta Ciudad del Este.

La decisión de migrar a la capital argentina la habían tomado María y el marido. Buenos Aires era un destino migratorio con mejores ofertas de sueldo: tanto en comparación con las ciudades paraguayas más cercanas a su pueblo de origen (Ciudad del Este, por ejemplo), como con la ciudad brasileña (Foz) y la argentina (Puerto Iguazú). Pero la decisión no había estado orientada sólo por criterios económicos: María y su esposo contaban con una densa red de familiares y amigos emigrados a Buenos Aires, y esto facilitaba el proceso. Tenían la casa de unos tíos y primos donde hospedarse hasta acumular recursos para alquilar una vivienda. Así, fueron a vivir al municipio de Florencio Varela (conocido enclave de migrantes paraguayos, en la zona sur del Gran Buenos Aires): todos en su calle eran paraguayos y le encantaba vivir allí. Se sentía en Paraguay.

Empero, sus planes migratorios en Buenos Aires sufrieron una transformación. Su idea inicial era estar un par de años, ahorrarse dinero y volverse a Paraguay para poner un negocio. Justo cuando se preparaban para emprender el viaje de vuelta, se descubrió embarazada. Fue entonces cuando los cálculos del cuidado atravesaron los planes migratorios. Según María, los servicios médicos en Paraguay son muy caros: tener el hijo en Buenos Aires garantizaría una atención médica de calidad en el acompañamiento del embarazo, en los exámenes necesarios, en el parto y en los meses inmediatamente posteriores. Además, contaban con la cobertura de salud ("la obra social") vinculada al sindicato del rubro de la seguridad, en que el marido trabajaba. ${ }^{13}$ Así, en el cómputo de la relación entre los cuidados y los servicios de salud que podrían recibir en Argentina y en Paraguay, decidieron aplazar el regreso, para después del período postparto de María.

Pero tras tener al bebé - Ulises, el niño al que cuidaba en el viaje -, María escuchó de los médicos que él tenía discapacidades severas. No nos especificó cuál fue el diagnóstico exacto, pero el niño, ya con casi nueve años, parecía tener unos seis: era más pequeño de lo que se espera para su edad. Además, no caminaba solo,

\footnotetext{
12 Entre sus hermanas y hermanos, algunos trabajan con comercio, otros con construcción. Todos viven de manera "transfronteriza", entre Foz de Iguazú y Ciudad del Este.

13 Las “Obras Sociales” en Argentina son entidades que organizan la prestación de la atención médica ambulatoria, preventiva y de emergencia (en casos de enfermedad, accidente, discapacidad, licencia, embarazo, etc.) de los/las trabajadores/as asociados/as. Tanto el/la trabajador/a como su pareja (si estuviera desempleada) e hijos (hasta los 21 años, extensible a los 25 años) quedan cubiertos. Una ley nacional reglamenta que todas las personas con empleo deben gozar de obra social, estableciendo que el pago de estos servicios se hace con una contribución mixta del empleador y del/de la trabajador/a (descontada mensualmente en su hoja de pagos). La mayor parte de las obras sociales argentinas están administradas por los sindicatos: cada nicho laboral/profesional cuenta con una específica. Asimismo, el sistema nacional provee de la red de hospitales públicos (gratuitos) y las Obras Sociales Nacionales, Provinciales (para desempleados, trabajadores informales sin contrato, población vulnerable, indigentes) y el Programa de Atención Médica Integral-PAMI, que brinda atención sanitaria a jubilados y pensionados (Maceira, 2006:2).
} 
tenía dificultades motoras para sostener sus juguetes, y estaba mucho rato mirando en silencio al vacío. Hablaba con pocas palabras, que repetía constantemente. La más frecuente - "mamá" - nos hizo suponer que María era su principal referencia afectiva adulta.

El diagnóstico dela discapacidad de Ulises fue una dura noticia, dijo María. Todos los planes de futuro sufrieron una inflexión. Los médicos afirmaban que el niño iba a necesitar de atención especializada vitalicia. La única manera de garantizarle un mínimo de bienestar era una atención permanente de kinesiólogos, psicoterapeutas, psicopedagogos y neurólogos especializados. Aquí, la medición comparativa de las posibilidades de cuidado apareció, una vez más, como ejercicio central en la orientación de la decisión migratoria. Contrastando los costes y la calidad de la atención que podrían brindar a Ulises en Argentina y Paraguay, decidieron quedarse en Buenos Aires.

María confesó que ella y su marido jamás se plantearon la posibilidad de criar un hijo en Argentina: preferían que sus hijos crecieran en Paraguay. Pero las necesidades de cuidado de Ulises reconfiguraron estas preferencias. Los servicios de salud en Paraguay eran tan malos - decía - que llevar el niño a ese país sería "someterlo a la tortura", a pésimas condiciones de vida. "En Paraguay, el que tiene dinero, vive; y el que no tiene dinero, muere". Nos contó que, sin recursos para pagar la cobertura de salud, difícilmente podrían tener buena atención médica en Paraguay, donde incluso la salud pública es paga. Además, decía, faltaban especialistas, equipos, insumos y medicinas adecuados.

En contrapartida, María evaluaba que los servicios de salud pública en Argentina eran "de primera calidad" y "gratis" (es decir, pagados con los impuestos, pero sin requerir de los contribuyentes nuevos desembolsos al momento de recibir dichos servicios). Así, además de contar con la asistencia de salud de la "Obra Social" a la que tenían acceso por las contribuciones laborales de su marido, María contaba con una amplia red de profesionales de la salud en los servicios públicos de la capital argentina. Su hijo tuvo el acompañamiento de una neuróloga experta, que atiende en un hospital público considerado una referencia internacional en discapacidades. Esta misma doctora cuidó continuamente a Ulises desde que nació. Quedarse en Buenos Aires fue, entonces, una decisión tomada para permitir que Ulises tuviera "todas las atenciones médicas que necesitaba".

Como nació en Argentina, Ulises es ciudadano argentino, además de ser también paraguayo (por la nacionalidad de sus papás). Desde que nació, cobra la pensión social por invalidez, un derecho garantizado por ley en Argentina y que, decía María, no existe en Paraguay. Nos explicó, además, que había diversas leyes argentinas pensadas para "cuidar a la gente". Por ejemplo, debido a su discapacidad, Ulises tenía derecho a viajar de ómnibus por todo el país sin pagar el pasaje: las empresas le dan gratis el boleto, y deben concederle dos más (para los acompañantes). Así, podían tomar el ómnibus los tres - ella, Ulises y el padre - para estar con la familia en Paraguay en las vacaciones de invierno. Esto les facilitaba poder ir más veces a estar con la familia durante el año (y María podía contar con la ayuda de sus hermanas en el cuidado del pequeño).

No obstante, ella opinaba que con la presidencia de Mauricio Macri (2015-2019) todo había empeorado: se había vuelto muy difícil pagar la cuenta de la electricidad, del gas; no había empleo y ella esperaba, "sinceramente", que Argentina cambiara "de rumbo político con las próximas elecciones". Nos aseveró que esta crisis había afectado a la salud pública, que empeoró flagrantemente. Empero, incluso así, seguía mucho mejor que la paraguaya. Observamos, entonces, que los cómputos comparativos de acceso al cuidado en los servicios de salud que realizaba María orientaban sus posicionamientos sobre los contextos políticos nacionales.

Aproveché estos comentarios para decirle que, desde mi perspectiva, las mujeres sufrían más en estos momentos de crisis, pues, cuando el Estado deja de prestar servicios públicos, son ellas quienes generalmente deben resolver su ausencia, buscar atenciones/soluciones alternativas. Apenas terminé de hablar, María me hizo señas con los ojos - sin girar la cabeza, sin moverse apenas -, apuntando con este sutil movimiento a su marido al lado. Y, después de este movimiento contenido, esos mismos ojos sutiles se llenaron de lágrimas. María me hizo que sí con la cabeza, pero no profirió palabra. Entendí que concordaba, pero no podía decirlo en voz alta. 
Parecía que el intenso cuidado que la vimos entregar al hijo en las dos horas de viaje estaban vinculados con estas lágrimas y con estas palabras contenidas. Ella no podía enunciar a voz firme, al lado del marido, que las mujeres están sobrecargadas de trabajo. Su propia sobrecarga no podía ser puesta en la mesa de diálogo. Esta apreciación sobre su obligación moral de aceptar la sobrecarga silenciosamente nos acompañó las 20 horas del viaje. Sólo vimos al padre interactuar brevemente con el niño una única vez, cuando este dijo "papá".

Lo que María sí pudo contar es que, desde que había tenido a Ulises, ya no podía trabajar fuera de su hogar. Antes del embarazo lo hacía, y tenía un buen sueldo, pero Ulises demandaba cuidados presenciales intensivos todo el tiempo: no era viable pagar a alguien para realizarlos. Ese servicio saldría muy caro, superando incluso el sueldo que ella recibía. Frente a la imposibilidad de tercerizar los cuidados de Ulises a otra mujer - y sin que se planteara la posibilidad de que padre y madre los compartieran - María se había visto obligada a encargarse de este "caro servicio" (aunque sin un sueldo que reconociera su labor). La solución reproduce la ideología familista - y patriarcal - según la cual el mejor cuidado es el que entregan las mujeres de la familia (Glenn, 2010; Gonzálvez et al., 2019). Reproduce, además, la división de los cuidados por género, amarrando a la mujer a la responsabilidad de suplir trabajos esenciales para la reproducción social que el Estado, el mercado y los demás miembros de la familia no cubren.

Mientras hablaba de su destino como "cuidadora universal" de Ulises, me preguntó si yo tenía hijos. Respondí que no; que era muy difícil porque trabajaba muchas horas, no tenía a mi familia cerca (para contar con una red de apoyos). Eleonora, que también es migrante y vive lejos de su red familiar, dijo que tenía el mismo inconveniente y temía, además, no ser buena mamá. Asertiva, María nos contestó: "pero no tienen que saber ser madres. Una no nace madre, una aprende a ser madre". La frase reproducía uno de los principales argumentos de Simone de Beauvoir en "El segundo sexo", obra fundacional del feminismo:

No se nace mujer: se llega a serlo. Ningún destino biológico, psíquico o económico define la figura que reviste en el seno de la sociedad la hembra humana; es el conjunto de la civilización el que elabora ese producto intermedio entre el macho y el castrado al que se califica de femenino (Beauvoir, 2018:207).

Beauvoir estipula, con este argumento, que los mandatos, saberes y adscripciones de lo femenino no son, en absoluto, naturales. Son fruto de construcciones históricas que se aprenden, que se inculcan y que van dotando a las mujeres de una situacionalidad singular (singularmente oprimida, ironiza) (Beauvoir, 2018:16). María particularizaba esta apreciación, desafiando el sentido naturalizado de la maternidad en las mujeres. Y, liberándonos del miedo de no ser capaces de cumplir con los requerimientos "naturales" maternos, nos aseguraba que convertirse en una figura materna era un proceso y una decisión. Nos explicaba que estábamos a la altura de la maternidad; que no había nada que temer. Había que decidir si lo queríamos o no. María, la mujer a la que intuíamos sobrecargada por los cuidados, restringida a su desempeño en el ámbito doméstico; la misma mujer que momentos antes había llenado sus ojos de lágrimas al pensar en la sobrecarga femenina en un contexto de crisis social y económica; la mujer que silenciaba su opinión para no ofender la posición productiva del marido (que la escuchaba sin proferir palabra) nos informaba, minutos después, que había elegido su maternidad. En un contexto adverso a cualquier manifestación de la voluntad propia, ella nos situó su nicho de agencia. Decidió ser madre y se hizo madre.

Su reflexión no se detuvo ahí. Cuando la escuché proferir la frase, repetí en voz alta la de Simone, "una no nace mujer: llega a serlo". Inmediatamente, mirándome a los ojos, y aprovechando que el marido había ido al baño, María completó: "sí, a los golpes. Una se hace mujer a golpes; la vida de las mujeres es muy difícil". Seguimos conversando hasta que el bus se puso en movimiento. Entonces, Eleonora y yo nos apresuramos, le dimos un beso a María y fuimos a sentarnos. Cuando llegamos a Puerto Iguazú, le di un abrazo y le dije al oído: "Ojalá puedas descansar en estas vacaciones". 


\section{Amarena}

Eran casi las 11:0o hs del lunes 15 de agosto de 2019 cuando llegamos a Puerto Iguazú. Al bajar del ómnibus, luego de 20 horas de viaje y sin haber desayunado, ${ }^{14}$ Eleonora y yo decidimos comer algo en la terminal de buses, antes de proseguir nuestro viaje hacia Foz de Iguazú, donde nos hospedaríamos. Entramos, entonces, a una de las cafeterías de la estación. Nos atendió Amarena: simpática joven argentina que - nos enteraríamos más tarde - acababa de cumplir 26 años. Con cordialidad, nos habló de las opciones de merienda y esperó atenta nuestra decisión.

Mientras comíamos, hicimos algunas preguntas sobre la terminal. Amarena se puso curiosa por conocer el motivo de nuestro viaje. Le explicamos que estábamos desarrollando un estudio sobre mujeres en las fronteras; le preguntamos si no le gustaría concedernos una entrevista. Consintió que lo hiciéramos mientras ella trabajaba (pausaríamos la grabación para que atendiera a los clientes). Estuvimos con ella por casi tres horas en las que, con enorme generosidad, nos contó su vida.

Amarena nació y creció en Puerto Iguazú. Sus padres, no obstante, eran migrantes internos en Argentina. La madre era de Mar del Plata (en la provincia de Buenos Aires), hija de un trabajador de una cadena de casinos, ocupación que le obligaba a migrar desplazándose a las ciudades argentinas donde sus servicios eran requeridos. Su familia materna había experimentado años de intensa movilidad nacional, residiendo en lugares tan distantes como el Chaco argentino y la patagónica provincia de Chubut. Pero en los 198os, trasladaron a su abuelo a Puerto Iguazú y la vida allí les encantó: decidieron fijar residencia. Desde jovencita, su mamá había conseguido empleo en una farmacia de la ciudad, donde aún trabajaba. Su papá, por su parte, era de la ciudad de Santa Fe (capital de la provincia homónima). Migró a Puerto Iguazú para trabajar en servicios turísticos y fue precisamente empleado en el rubro compartido con su ahora suegro que conoció a la madre de Amarena. Se enamoraron, se casaron, tuvieron su única hija y llevaban juntos casi tres décadas.

Según Amarena, desde el matrimonio hubo, entre sus progenitores, un acuerdo de división del trabajo hogareño. Su madre jamás se planteó dejar su empleo para hacerse cargo sola del cuidado de la casa y de la hija. Así, organizó con el marido un sistema de tareas compartidas y ambos pudieron mantener sus empleos y conciliarlos con tales tareas. Amarena tuvo una infancia tranquila, terminó la educación secundaria en Puerto Iguazú. Después, eligió cursar diseño gráfico, para lo que debió trasladarse a la ciudad de Oberá (provincia de Misiones, a 268 km. de Puerto Iguazú). Estudió allá un año en una escuela técnica terciaria, hasta decidirse por intentar la universidad, en la ciudad de Resistencia (capital de la provincia de Chaco). Allá cursó por cuatro años más.

No obstante, su padre se enfermó y estuvo muchos meses de reposo, sin poder trabajar. La situación económica de la familia empeoró y Amarena, entonces con 21 años, interrumpió sus estudios en el último año de la carrera: regresó a Puerto Iguazú para ayudar a su mamá en el cuidado de su padre, y para trabajar, contribuyendo económicamente con su familia. Su carrera se quedó truncada. Consiguió un empleo como vendedora del Duty Free Shopping de Puerto Iguazú, donde trabajaba 12 horas diarias, aunque por un salario relativamente elevado (particularmente en las temporadas turísticas, debido a la afluencia masiva de compradores brasileños). Fue allí donde Amarena aprendió mejor el portugués - que habla de manera fluida y casi sin acento -. Desde pequeña, entendía e incluso hablaba portugués porque, según decía, en Puerto Iguazú “todos ven la televisión brasileña y escuchan música brasileña”. Pero en el Duty tuvo que pulir muchísimo su acento: los/las brasileños/as no entienden el castellano, ni quieren ser atendidos en un idioma que no sea el suyo. Como son la mayoría absoluta entre los clientes, los gerentes presionaban las vendedoras a que aprendieran "un portugués ejemplar".

14 Nuestras provisiones se terminaron y no quisimos bajar en las rápidas pausas del colectivo en la Provincia de Misiones. 
Según Amarena, los/las brasileños/as vienen a Puerto Iguazú a comprar perfumes y diversos productos importados. Pero, dada la crisis económica de Argentina, las mujeres cruzaban al lado brasileño para abastecer a sus hogares: los alimentos estaban mucho más baratos allá. Computando la rentabilidad de sus recursos y las necesidades de su hogar, Amarena iba a Foz al menos una vez por semana a comprar arroz, leche y harina de trigo. Ella consideraba que los productos brasileños eran de menor calidad, pero sus precios eran convenientes. En un cómputo entre necesidades, posibilidades y calidad, resultaba conveniente comprar en Brasil. Pero este no era el único cómputo que la llevaba al lado brasileño:

Lo que es la salud, el hospital, conviene más allá. Todo lo que es clínica, odontología. El oculista también, voy allá [...]. Pero por el hecho de acá, en Puerto Iguazú, no es tan bueno. No sé por qué, nadie [ningún doctor] se quiere venir acá. Pero, realmente, yo he ido a [la Provincia de] Entre Ríos y es bien buena lo que es la salud argentina. Todo el mundo habla sobre eso. La salud pública en Buenos Aires es muy buena, la verdad que sí. A mí me pasó de ir a otros lados y, la verdad que, si te pasa algo, normalmente te vas a Posadas [capital de la provincia de Misiones]. Pero es muy lejos. Realmente es muy lejos; por eso, siempre te vas a Brasil [...]. Y el oculista también. Fui a Posadas y fui a Entre Ríos y era muy bueno. Acá [en Puerto Iguazú] es el problema [...]. La verdad es que en Brasil [los médicos] te tratan de la misma forma [que tratan a los brasileños] [...]. La gente [en Brasil], es re-buena. La verdad es que, a mí, la doctora y los doctores que yo tengo te tratan por igual. No te tratan diferente.

Las demandas de Amarena por la salud brasileña se vieron incrementadas por una situación particular. Después de dos años en el Duty, ella fue a trabajar en una conocida heladería de Puerto Iguazú, donde su padre era gerente (para entonces ya estaba recuperado). El trabajo en la heladería era más tranquilo: buen sueldo, menos horas, contrato regular, con derecho a una obra social de calidad. La pusieron en un local en la terminal de buses y Amarena pudo aprender sobre la demanda de servicios en este espacio: sus potencialidades y ciclos. Trabajó allí dos años más, ahorrando dinero con la idea de ponerse una cafetería. Pero la decisión de iniciar su propio negocio vino por casualidad: ella se embarazó.

Venía recién iniciando una relación amorosa. Con una pareja anterior, había intentado embarazarse, aunque sin éxito. Tras varios intentos fallidos, los médicos de Puerto Iguazú le aseguraron que tenía problemas que le impedirían terminantemente tener hijos/as. Esta imposibilidad separó a la pareja y, tiempo después, Amarena conoció a su actual compañero. Tomaba píldoras contraceptivas cuando empezó a notar problemas con el volumen de su menstruación. Fue al médico, que le indicó, dado que no podía tener bebés, que dejara de tomar los contraceptivos, para observar cómo su cuerpo respondía. Un mes después, estaba embarazada.

Tuve [el test] como tres días. Viste que comprás y vos esperás: "capaz que hoy sí, capaz que hoy no". Y, bueno: levanté un día en la mañana y fui: lo hice y estaba [embarazada] [...]. La verdad es que estaba re-contenta y recuerdo que lo primero que pensé, y lo primero que me pasó por la cabeza, fue el parto.

La negligencia del médico de Puerto Iguazú - con su recomendación de interrumpir el contraceptivo - era grave, dijo. Pero no pudo enojarse: embarazarse era algo que había deseado muchísimo. Pero no quería confiar el acompañamiento de su embarazo y el parto a los médicos de su ciudad. Su madre trabajaba en una farmacia al lado del centro clínico donde se atienden a las mujeres embarazadas. Allí, había sido testigo de incontables casos de negligencia:

Ahí ves un montón de cosas. Ahí ves mala praxis. Y ves gente que no se sabe cuidar: mujeres que no se saben cuidar; mujeres que perdieron bebés de forma tan fea y tan tonta. A veces, por el doctor, a veces por las personas. Entonces, me dio mucho miedo. Tuve mucho miedo, miedo del parto; porque no sabía si quería cesárea o normal. ¿Viste? No quería que me duela y tampoco quería que sufriera el bebé. ¡Ah! Estaba con miedo. 
La conocida negligencia de los médicos de la ciudad, el hecho de conocer tantas mujeres que habían perdido a sus bebés en el parto, o durante el embarazo, provocó que, tras la emoción de saberse embarazada, Amarena fuera tomada por el pánico. El miedo es, entonces, la respuesta emocional (personal, incorporada) a la violencia del sistema público de salud hacia las mujeres. El miedo es también una respuesta auto-protectiva: Amarena decidió no entregar su salud y la de su bebé a los médicos de su ciudad. Una violencia (la negligencia médica), un sentimiento (el miedo) y una acción (cruzar la frontera para parir):

Hablando un poco con otras personas, y bueno, "este médico aquí me hizo asî” [...]. Hay médicos que tienen un montón de historias, malísimas. Allí agarré... me dio más miedo [...]. Hay un doctor, por ejemplo, que le pasó... que se le cayó el bebé de los brazos ¿Viste? La mujer estaba teniendo y el bebé lo sacó y se le cayó. Y se murió. Hay otro bebé que escuché que lo dejaron mucho tiempo en la panza y la mujer estaba pujando, estaba pujando y nadie la ayudó, y el bebé nació con un problema en el cerebro por falta de oxígeno. Entonces, cosas así que te dan miedo: doctores que le pusieron mal la epidural [anestesia] a algunas mujeres y el bebé le agarró la anestesia y cosas así que te dan miedo. Entonces, siempre me atendí en Brasil.

Hubo, además, dos historias muy cercanas que la impresionaron mucho. La primera, de una compañera de trabajo de su madre, que le insistía que fuera a atenderse en el hospital "Costa”, en Foz de Iguazú, del lado brasileño. El "Hospital Ministro Costa Cavalcanti” (HMCC) - popularmente, "el Costa" - es reconocido en Brasil como uno de los mejores del país. Fue creado en un momento de despliegue del Estado nacional, con la expansión de complejos públicos brasileños en la Triple Frontera, vinculados a la construcción de las infraestructuras energéticas. ${ }^{15}$ Así, el hospital era parte de un plan de hegemonía estatal brasileña, y sigue constituyendo una supervivencia de un despliegue de la presencia del Estado - estrategia que dejó de constituir un vector político nacional en los años 199os, con las reformas neoliberales $-{ }^{16}$. Atendiendo tanto a la red pública de salud, como a la privada (a través de los "planes de salud" brasileños, los seguros de salud paraguayos y a las obras sociales argentinas), "el Costa" es la principal referencia de atención sanitaria en la conurbación transfronteriza del Paraná. Amarena nos contó que su obra social le permitía atenderse allí.

La amiga de la madre de Amarena le confesó que había hecho todo el acompañamiento del embarazo en Puerto Iguazú y que, al momento de tener el bebé, los médicos no lo encontraron en el útero y decidieron enviarla al Costa en una ambulancia. Allá, atendida en emergencias, fue informada de que tenía un embarazo ectópico - el bebé se había formado en la cavidad abdominal, y no en el útero -. No lo habían detectado en Puerto Iguazú en los meses de prenatal. Ella terminó perdiendo su hijo: había llegado tarde al hospital brasileño y ya no era posible salvarlo.

El segundo caso drástico fue el de su prima, que se embarazó al mismo tiempo que Amarena y fue maltratada en la atención pública argentina. Ella había desarrollado diabetes gestacional y los médicos la pedían que bajara más de 10 kilos, cosa que le resultaba imposible (toda la vida había tenido sobrepeso y, al momento de embarazarse, pesaba 220 kilos). Como no lograba adelgazar, se negaban a atenderla.

15 El hospital fue inaugurado en 1979, propulsado por la empresa Itaipú Binacional (que construyó y gerencia actualmente la Hidroeléctrica de Itaipú). Inicialmente, el hospital atendía a los trabajadores empleados en la construcción de la planta eléctrica. Sin embargo, "fue mucho más allá de su misión original y se convirtió en una referencia de salud para una gran región. En 1994, se creó la Fundación de Salud Itaiguapy para administrar el Hospital. A partir de este año, éste se ha sometido a una serie de reformas estructurales para proporcionar el más alto nivel de atención hospitalaria en la región. En 1996, el HMCC comenzó a atender a pacientes del Sistema Único de Salud (SUS) [sistema público brasileño] y actualmente, más del 6o\% de la atención es para usuarios del SUS”. (Hospital Ministro Costa Cavalcanti 2019: s/p. La traducción me pertenece).

16 A diferencia de Argentina y Paraguay, la dictadura militar brasileña (1964-1986) no institucionalizó las reformas neoliberales de reducción del Estado. El militarismo brasileño adoptó una perspectiva estatizadora de la economía, promoviendo una industrialización primaria, invirtiendo sendos recursos en la infraestructura portuaria, de transportes e industrial general. Todos estos aspectos integraban un plan de control social y territorial dictatorial. Foz de Iguazú constituyó uno de los principales enclaves condensadores de esa política militar. 
Amarena la convenció de que se atendiera en Brasil; la llevó y acompañó personalmente a cada consulta. Allá, dice, los doctores no la castigaban por su sobrepeso, sino que adoptaron una estrategia de reducción de daños que resultó respetuosa de las circunstancias psicológicas de su prima.

Desde ahí fue que yo le llevé a mi prima, totalmente. ¡Porque yo me sentía tan bien cuando iba [a Brasil]! Sentía que también... A ver: vos te vas acá y hay tanta gente que va al médico. Y los médicos no dan abasto, porque realmente no dan abasto. ¿Cómo te digo? Realmente, son muy pocos, estás horas y horas y horas esperando. Y para una mujer embarazada, es un problema. Allá ¡no! Allá, vos estás embarazada, tenés una persona que te atiende aparte, para sacar número o para lo que sea. ¡ Es un montón de todo! Cosas distintas, que no hay acá. Entonces, si vas, estás casi cuarenta minutos viajando hacia el Costa, porque ir de acá hasta allá es lejos. Pero sabés que vos vas a llegar y te tienen que atender a las 15:20 y estás a las 15:10 y ya te están atendiendo. Es distinto. Es distinto a que vos llegues acá [en Puerto Iguazú] a las 15:10 y te tenían que atender a las 15:20 y son las 17:00 y todavía no te atienden. Y tenés que volver a trabajar... Entonces, en esos casos, sí o sí, tenés que atenderte allá. Yo me atendí allá y, por suerte, no tuve ningún problema.

Pese a haber elegido atenderse en Brasil, minimizando así los problemas con su empleador, Amarena percibió que sería imposible conciliar la maternidad con su trabajo. Los tiempos no eran flexibles en la heladería: difícilmente podría contar con la comprensión necesaria para salir a amamantar a su bebé, por ejemplo. Consecuentemente, puso en práctica la idea de poner una cafetería en la terminal de buses y compartir con su pareja el trabajo. Pidió la opinión de su padre, quien tenía mucha experiencia con negocios en Puerto Iguazú y él, convencido de que era una buena inversión, la ayudó económicamente. Así, el local donde comimos ricas empanadas era la microempresa de Amarena.

La hija de Amarena nació un viernes, de parto natural. Apenas sintió las contracciones, se trasladó al lado brasileño, donde la esperaba su doctora. Fue un parto tranquilo, dijo. Con mucho menos dolor de lo que había imaginado. La atención fue "genial", aseveró. La gente "la cuidaba con mucho cariño allá", en Brasil. Le pregunté, entonces, por la parte burocrática de este nacimiento transfronterizo: al nacer en territorio brasileño, su hija tenía derecho a la nacionalidad del país vecino. Amarena aseguró que eso no había entrado en sus cómputos durante el embarazo. Pero con su pareja hicieron igualmente el trámite de nacionalidad de la nena, pues facilitaría la continuidad de la atención sanitaria en Brasil.

Tras el nacimiento, tuvieron que esperar hasta el lunes (las reparticiones públicas brasileñas ya no atendían). Amarena seguía internada en el hospital, por lo que su pareja hizo el registro de la pequeña, habilitando todos los papeles para cruzar la frontera con la niña y para registrarla en Argentina. Según ella, antes estos trámites eran mucho más sencillos. Pero, ahora, el cruce de un bebé por la frontera se había complejizado:

Esto de tenerle [a los/as hijos/as] en el Costa empezó desde hace mucho. O sea, yo tengo amigas que nacieron en el Costa. Desde esa época, hace 20 años atrás. Y no era tan difícil pasar el bebé [hacia Argentina]. Ahora está muy difícil. No era tan difícil. Aparte, porque había mucha más plata en Iguazú. Antes había muchísima plata en Iguazú: el que trabajaba con cuero tenía mucha plata y podía ir a gastar en Brasil y traer el bebé no salía tan caro. Ahora no hay tanta plata en Iguazú: tenés que tener una muy buena obra social, como yo, que tengo mi obra social, y, aparte, la plata para traerle al bebé [para pagar las tasas de los trámites]. Por suerte, ahora no tenés que ir a ningún lado para hacer el registro de nacimiento [...]. Todo eso lo podés hacer, por suerte, en el hospital [en Brasil]. Antes, no. Antes, tenías que ir al notario. Ahora, no. Entonces, ella nació un viernes. Así que era viernes. Sábado y domingo no había servicio [...]. Cuando salí de esos tres días, salimos e hicimos el trámite. Sí, ahí fue que fuimos al registro y me dieron los papeles [...]. De ahí nos fuimos a la aduana [argentina] yo pase y él [su pareja] se quedó haciendo los trámites de pagar, de mostrar que el bebé está. Pero también conozco gente que lo pasó tipo así, medio por abajo. O sea, no pasás caminando, pasás en el auto. Entonces, pasás en el auto y, ponéle, que no le bajás el vidrio. Entonces, [el oficial fronterizo] no ve que está el bebé ahí. Pero no te sirve, porque vos después tenés que venir 
acá y tenés que tener algo para ir a presentar... La partida de nacimiento de tu bebé para que te hagan... No podés estar así. Como pasaste el bebé, te pueden hasta meter preso por sacar el bebé. Pero hay mucha gente que lo hace y anda sin documento el bebé años. Entonces dije: "voy a hacer las cosas bien". Porque yo también pensaba seguir atendiéndome allá, atendiéndola a ella. Entonces necesitaba, sí o sí.

Trabajando entre 12 y 14 horas diarias en su local, Amarena sigue cuidando a su pequeña y haciéndola atender en el sistema de salud brasileño. Lo único que hace en Argentina es ponerle las vacunas, porque "las argentinas son muy buenas". Todos los días por la mañana venía con la nena de cuatro meses en su auto y la dejaba en la casa de su abuela materna, a dos calles de la terminal. La amamantaba y salía a abrir la cafetería. A cada tres horas, salía de su negocio para amamantar. En estos momentos, su padre o su pareja venían a sustituirla. Amarena estaba muy tranquila con estas soluciones, porque su abuela la había criado a ella también. Su mamá siempre había trabajado, y cuando tuvo a su única hija, contó con el apoyo de su progenitora, para seguir desempeñando una función productiva. Así, el ejemplo de su madre enmarcaba la actual configuración del equilibrio cuidados/actividad productiva para Amarena. El trabajo de su abuela permitía - como lo hiciera una generación antes - que este equilibrio fuera posible. Tenemos, así, tres generaciones de mujeres implicadas en un sistema de prestación total del cuidado (Comas, 2017) - un sistema de dones, en términos antropológicos - que permitía la reproducción de la familia, el cuidado de las menores (siempre mujeres) y la vida productiva de la red familiar.

\section{Bernadette}

Mañana del martes 16 de julio de 2019. Amanecimos - Eleonora y yo - en Foz: habíamos cruzado al lado brasileño desde Puerto Iguazú en la tarde anterior. Eran las ocho cuando salimos del hotel hacia la Avenida Juscelino Kubitschek. ${ }^{17}$ Habíamos avanzado dos cuadras cuando avistamos un templo de la Iglesia Universal del Reino de Dios (IURD). La "Universal", como es conocida en Brasil, es una congregación religiosa evangélica, neo-pentecostal, fundada en 1977, en Río de Janeiro, por el entonces pastor (hoy obispo) Edir Macedo. Con una rápida expansión, la congregación prontamente llegó a todos los estados brasileños. En el censo del 2010, apareció con alrededor de 6.000 templos, 12.000 pastores y aproximadamente un millón de devotos (IBGE, 2010). Casi una década después, es posible suponer que estos números son significativamente mayores, dado el despliegue de la IURD en tres campos centrales.

El primer campo es el comunicacional: la congregación generó lo que en Brasil se considera un imperio multimedia de comunicación y difusiones. ${ }^{18} \mathrm{El}$ segundo es el político. La IURD construyó una ingente plataforma de representación política por todo Brasil: sus pastores y obispos ocupan cargos en los poderes legislativos de varios municipios y estados, y están plenamente representados a nivel federal. En este último constituyen actualmente una influyente fuerza política, compartida con representantes religiosos de otras congregaciones y conocida popularmente como "la bancada evangélica" (formalmente denominada "Frente Parlamentario Evangélico"), que detenta alrededor del $12 \%$ de las bancas de diputados en el Congreso Nacional (Machado \& Burity, 2014:601). Su presencia política también es muy representativa en los cargos ejecutivos municipales (pastores y obispos vienen aspirando incluso a cargos ejecutivos estaduales y federales) (Machado \& Burity, 2014). Actualmente, la IURD tiene un papel político central: está entre las fuerzas evangélicas con mayor

\footnotetext{
17 El hotel donde nos hospedamos está localizado en la esquina de las avenidas Argentina y Juscelino Kubitschek. Este cruce marca el final del centro de Foz e inicio de una zona urbana de transición, que se extiende hasta el barrio Vila Portes, donde se encuentra el Puente de la Amistad, que conecta con Paraguay.

18 Posee más de 70 estaciones de radio, una sintonía de televisión (la "TV Universal”) cuyos programas son retransmitidos por 20 emisoras en todo el territorio nacional; un portal de Internet (el "Universal.org"); un diario impreso y tres revistas. Tiene, además, una editorial propia, que publica las obras de los pastores con una amplia distribución nacional. Asimismo, Edir Macedo, juntamente con otros obispos de la IURD, son propietarios de la segunda cadena de televisión abierta con más rating en Brasil: la TV Record. Las emisoras de radio y televisión que difunden su señal constituyen la cadena difusora más extensa del país, superando a la Rede Globo que, desde la dictadura, fuera la más importante en el territorio brasileño.
} 
influencia junto al Presidente de la República, Jair Bolsonaro. Está promoviendo, en alianza con otras fuerzas evangélicas, un giro a la extrema derecha en los posicionamientos morales, jurídicos y económicos del Congreso Nacional, particularmente con relación a la planificación de las políticas familiares y de seguridad. El tercer campo es el transnacional. Desde los años 1980s, la IURD viene realizando un proceso de transnacionalización (Oro 2004). Actualmente, tiene una presencia relevante en Estados Unidos; en Argentina y en Portugal; en Sudáfrica, Uruguay, México y Francia (Oro, 2004). Según el obispo Domingos Siquiera (2015), la congregación contaría con 8 millones de seguidores en el mundo, y más de quince mil pastores diseminados por 105 países.

Decidí acercarme al templo de la IURD que vimos en nuestro trayecto cuando observé que dos mujeres afrobrasileñas conversaban animadamente en la puerta. Estaban vestidas según el código de la congregación: faldas hasta los pies, camisas de manga larga, pelos rigurosamente estirados y tomados en un estricto moño. Ambas tenían biblias bajo los brazos.

Ingresé al predio de la congregación, cruzando junto de Eleonora el amplio estacionamiento del patio delantero, y me acerqué a la mayor de las mujeres. Le expliqué que éramos investigadoras, que hacíamos un estudio científico para comprender cómo viven las mujeres en la Triple Frontera. La señora se mostró instantáneamente entusiasmada: se llamaba Bernadette, nos contó, y agregó que su compañera era Alicia. Al ver su entusiasmo, les expliqué que queríamos entrevistarlas para saber cómo habían vivido y cómo vivían actualmente. Antes de que pudiera completar la idea, Bernadette se apresuró: “iyo puedo contarte mi historia ahora mismo! Yo nací...”. Preocupada de que nuestra intervención sin pedir autorización al pastor pudiera resultar una falta de respeto a los códigos y ordenamientos de la congregación, la interrumpí: "calma, señora Bernadette. Primero tenemos que explicarle algunos datos más de nuestra investigación y pedir la autorización del Pastor para realizar entrevistas aquí".

Ajena a mis reparos, Bernadette siguió su narración. Había nacido en el estado de Minas Gerais (en el interior brasileño, a unos 1.400 kilómetros de la Triple Frontera). Se trasladó muy pequeña a Foz, acompañando a sus padres, agricultores sin tierra, jornaleros (trabajaban y cobraban por día, sin contrato laboral) para terceros (es decir, integraban el sector más pobre entre los trabajadores rurales del país). Pues bien: sus progenitores migraron a Foz para trabajar en el campo, en la agricultura de pequeña y mediana escala que se practicaba en los municipios cercanos. Pero la inundación de los campos para la puesta en marcha de la Hidroeléctrica Itaipú desintegró las propiedades agrícolas del entorno, expulsando a sus propietarios hacia el lado paraguayo. Allí, el valor de las indemnizaciones entregadas por el Estado brasileño por la pérdida de las tierras rendía más, permitiendo que adquirieran propiedades más amplias. Los padres de Bernadette no estaban entre estos propietarios: ellos integraban la masa de trabajadores precarizados que prestarían servicio a estas nuevas chacras y haciendas brasileñas en tierras paraguayas. Como muchos otros trabajadores sin tierra, se desplazaron desde Foz a los pueblos rurales aledaños al río Paraná, en el departamento paraguayo de Alto Paraná, donde las colonias brasileñas crecieron, implementando campos de cultivo agrícola donde antes había solamente selva.

Bernadette había pasado la mayor parte de su vida - más de treinta años - del lado paraguayo, trabajando en el campo con sus padres y hermanos/as. Vivía allí desde que tenía memoria, pero hacía diez años ella y toda su familia habían migrado de vuelta al lado brasileño, a Foz de Iguazú. (Bernadette aparentaba más que los 45 años que relataba tener). Me contó, asimismo, que sufría de muchos problemas de salud (complicaciones de la epilepsia que padecía desde niña) que fueron centrales para su decisión de regresar a Brasil. ${ }^{19}$ La atención médica en Paraguay, decía, era inexistente.

19 La narración de Bernadette coincide con los estudios de Giovanella et al. (2007:256), que indican que los consultorios y hospitales públicos brasileños (del S. U. S. ), en las ciudades fronterizas con Paraguay, reciben una demanda mayoritaria de ciudadanos/as brasileños/as, que residen del lado paraguayo de la frontera y se emplean, de manera informal e indocumentada, en la agricultura en territorios paraguayos. 
Así, en los últimos diez años, venía buscando atenderse en la red pública brasileña de salud: había visitado numerosos médicos, que no lograban dar con un diagnóstico ni con un tratamiento adecuado a su problema. Las crisis de epilepsia se fueron agravando, provocándole secuelas motoras, de coordinación, dificultades de movilidad e incluso períodos de parálisis (tras un fuerte ataque epiléptico, perdió durante meses los movimientos de su cuerpo).

Su aseveración sobre el sistema público de salud en Foz era contundente: "no les importan los pobres". Pero no se trataba solamente de esto, sino de algo fundamental: "los doctores, los médicos, no saben cómo cuidar". Cada vez que ella iba al médico del sistema público, eran horas de espera, con hambre, sin tener dónde sentarse ni un baño disponible. Cuando finalmente la atendían, apenas la miraban a la cara; no le preguntaban siquiera cómo estaba, qué sentía. Tanta "desatención”, decía, "tanta falta de interés", tenía como consecuencia que nunca lograban subsanar sus problemas ni medicarla correctamente. Así, sus crisis iban aumentando, en la misma proporción en que los médicos la iban sometiendo a más y más exámenes, que implicaban incontables horas de espera, en filas interminables. Diez años de esto agotaron a Bernadette: "yo me cansé de ir al médico. Descubrí que lo que necesito es amor de verdad".

Había encontrado este tipo de cuidado, este amor verdadero, en la Iglesia Universal del Reino de Dios. Había acudido a varias congregaciones religiosas de todos los tipos - evangélicas, católicas, espíritas -. Pero sólo en aquella sede de la IURD, donde estábamos, encontró un pastor que la cuidaba como ella quería:

Mi pastor, cuando ve que estoy mal, él percibe que estoy mal. Él percibe que no me siento bien, se da cuenta. Me pregunta cómo estoy. Sabe mi nombre y, cuando sabe que no estoy bien, me hace la oración para espantar de mí los malos espíritus. Para que ellos no me vuelvan a enfermar.

El pastor siempre se apresuraba a exorcizar los malos espíritus que eran "responsables de su epilepsia". Además, cuando su salud empeoraba, él se encargaba de hablar con las demás hermanas de la congregación para que la cuidaran: para que la atendieran, la ayudaran a sentarse para las oraciones, la acompañaran desde y hacia su casa. El pastor organizaba, entonces, un turno de atenciones entre las hermanas y hermanos que se hacían cargo de Bernadette, de preguntarle diariamente cómo estaba y si necesitaba "algo más". De ser así, estos hermanos/as la atendían. Bernadette nos contó que encontraba en este pastor, y en esta congregación, el lugar de cuidado y de "amor de verdad" que no estaban disponibles ni en el servicio público de salud, ni en su familia.

Su madre no aprobaba que ella fuera a la IURD: como los demás miembros de su núcleo familiar, decía que estos pastores le estaban sacando el dinero. Su familia no terminaba de entender que ella "recibía cuidados" en el templo. Sentía que no la apoyaban: que ella había cuidado a todos - hermanas, hermanos, madre, padre - y que no recibía de ellos nada a cambio. No entendían sus necesidades de cuidado.

Bernadette vivía en un barrio pobre de la periferia de Foz a una distancia considerable del lugar en que estábamos. Allí, como en casi todos los barrios de la ciudad, también había templos de la Universal. No obstante, el pastor responsable por el templo de su barrio "no era tan bueno cuidando" como el que lideraba el templo de la Avenida Juscelino Kubitschek. En su barrio, el pastor no la atendía, no la miraba a los ojos, no hacía las oraciones cuando ella se sentía mal. Consecuentemente, ella decidió que él no era digno de recibir su diezmo valor de entre $10 \%$ y $20 \%$ del sueldo o renta mensual que los fieles deben entregar a los pastores de la IURD -. Tampoco lo consideraba digno de recibir su voto. Ella le dijo esto personalmente al pastor de su barrio: dado que él no sabía cuidarla, no le iba a entregar ni su dinero ni su voto; que lo haría en otro templo de la IURD, donde el "pastor cuida como se debe". 
Durante toda esta conversación, mientras Bernadette me hablaba, la señora Alicia nos escuchaba atentamente y tomaba notas. ${ }^{20}$ Eleonora, que no habla portugués, se esforzaba por entendernos. Volví entonces a interpelar Bernadette para decirle que sería genial entrevistarla con calma, que nos contara con todo detalle su vida, sus historias migratorias. Pero que queríamos pedir la autorización del pastor. Ella, entonces, nos condujo a la parte interna del templo. ¡Era enorme! Tenía las paredes amarillo claro, recién pintadas. Ingresamos al espacio principal, la sala donde se realizan las celebraciones: era muy luminosa, con asientos para unas 300 personas (en largos bancos de madera) que miraban hacia un gran altar cubierto por un mantel blanco delicadamente bordado. Unos segundos después, vino en nuestra dirección un hombre muy joven, saliendo de una puerta donde - según Bernadette - estaba la oficina de los pastores. Al verlo, me indicó que era el pastor, que podía hablarle del estudio.

El pastor se llamaba Felipe: no parecía tener más de 26 años. Me miró con desconfianza. Me presenté, le expliqué sobre el proyecto, que queríamos entrevistar a las hermanas de la congregación y también a los pastores. Su expresión de duda se profundizó: "no termino de entender qué quieres preguntar". Expliqué que nos interesaba entender los problemas que afectaban particularmente la vida de las hermanas de la congregación: las dolencias personales, espirituales, si había problemas de consumo de alcohol, de drogas. Si enfrentaban situaciones de violencia debido a los problemas de la criminalidad en Foz.

Entusiasmado con mi aclaración, me dijo que llegaba mucha gente "para ser libertada de las drogas y del alcohol". Llegaban, además, "enfermos de cáncer y nosotros acá les curamos con la fuerza de Dios. Curamos cáncer, tumores y otras enfermedades". Reiteré, tras escucharle, lo importante que sería entrevistar a los pastores y contar con sus testimonios. Él me explicó que pediría autorización al líder regional de la congregación, que se encontraba en la radio, donde tenía un programa diario. Intercambiamos contactos y Felipe me aseguró que, apenas tuviera una respuesta, me llamaría. Eleonora y yo nos despedimos de Bernadette y Alicia con un abrazo, explicando que esperaríamos la noticia del pastor para volver.

\section{Cuidadómetro}

Los diálogos con María, Amarena y Bernadette conducen a diversas constataciones sobre la relación entre las trayectorias de movilidad de las mujeres, su sobrecarga como cuidadoras y las configuraciones de las ciudades de la Triple Frontera del Paraná.

La primera constatación deviene del relato de María y permite establecer una interesante conclusión, sobre el lugar de las ciudades de la Triple Frontera como ejes articuladores de la migración transnacional (de media o larga distancia) de los/las paraguayos/as desplazados/as del campo. A luz de la historia de María, la apreciación realizada por diversos autores de estudios migratorios de que los más pobres de cada país no migran (Grimson, 2011:36), puede redimensionarse. Es cierto que las migraciones internacionales de larga distancia - desde la capital de un país a la de otro; o desde la periferia de un país a las zonas céntricas de otro implican la acumulación de diversos tipos de capitales (económicos, culturales o sociales) por parte de los/as migrantes. Pero esto no implica que la gente que no logra acumular estos capitales esté condenada a no migrar.

Como vimos en la trayectoria familiar de María, la migración desde el campo hacia Ciudad del Este configuró una alternativa para que sus hermanos/as pudiesen reunir los recursos necesarios para emprender otros tipos de migración. Si bien toda la familia estuvo involucrada en este éxodo campo-ciudad, sólo parte de esta emprendió una migración de larga distancia, hacia la capital argentina. Los capitales acumulados por la familia extensa son fundamentales para la consecución de este plan migratorio, actuando como una red de amparo en origen. Sin pretender suponer que todos los espacios fronterizos permiten este tipo de acumulaciones,

20 Me pareció curioso que ella registrara nuestra interacción, pero no le pregunté al respecto. 
es posible establecer que la Triple Frontera del Paraná sí lo hace - dadas las sus particularidades comerciales, territoriales, jurídicas y sociales -. El relato de María ejemplifica cómo las personas y las familias organizan este proceso de traslado, esta migración interna en Paraguay, y cómo esta territorialización en la frontera opera doblemente como trampolín a la migración hacia Buenos Aires y como un "puerto seguro" al que volver.

En segundo lugar, para nuestra protagonista, las decisiones sobre en qué momento y hacia dónde desplazarse dependen, centralmente, de sus cálculos sobre la cantidad y calidad de los cuidados que podrá dar a su núcleo familiar. María computa la posibilidad de acceder a servicios públicos de salud y las posibilidades de su pareja - y la propia - de trabajar con una remuneración suficiente para mantener las demandas de reproducción y cuidados de la familia. Entonces, los parámetros sobre el movimiento y sus temporalidades están dados por cómputos contextuales de los cuidados.

Tercero, la centralidad del cuidado como cosmovisión, para María, enmarca su perspectiva de la política. A partir de una demanda específica de cuidado (que su hijo tuviera buena atención de salud), ella desarrolló un posicionamiento sobre el gobierno nacional argentino. Así, su situacionalidad con relación al campo político estaba elaborada a partir de las necesidades micro-escalares cotidianas de cuidado de los seres de su familia, cuyas vidas estaban a su cargo.

El término "cuidadómetro" es la categoría que sugiero, entonces, para explicitar este sistema dinámico de medidas de cuidado que María establece a la hora de decidir cómo, hacia dónde y con quién moverse a través de las fronteras. El término me parece sugerente y es pertinente también para el caso de Amarena, quien aplica el "cuidadómetro" para estructurar un circuito de movilidad transfronterizo de corta distancia.

Tres aspectos fundamentales devienen de sus narraciones. Primero, su constatación de que la salud pública argentina, en otras regiones del país, es mejor que en Puerto Iguazú. Ella explicita que la fama nacional de la medicina argentina debe ser relativizada: en su ciudad de origen, los servicios brindados por el Estado distan mucho de ser comparables con los de Buenos Aires, o con las provincias de Santa Fé o Entre Ríos, e incluso, con la ciudad de Posadas (capital de la provincia de Misiones). La mención a esta última permite plantear que no se trata solamente de que Puerto Iguazú esté en una periferia del país, en una zona fronteriza. Posadas, ciudad capital de provincia, también es una ciudad fronteriza (con Paraguay) y - decía - tiene mejores servicios de salud. Así, la insuficiencia de los cuidados sanitarios en Puerto Iguazú respondería a cálculos macro-políticos que alguna vez hiciera el Estado argentino, evitando disputar abiertamente las pretensiones de hegemonía estatal brasileñas en la región (Grimson, 2002).

Segundo: hay también una apreciación diferencial de la especificidad de cuidados brindados en Brasil, en ciertos nichos sanitarios, como es el caso de la atención de gestantes. Amarena indica que, en esta última, hay "un montón de todo", refiriéndose a prácticas de cuidado puestas sobre diversos detalles del proceso de acompañamiento: desde evitar que las mujeres tengan que esperar las consultas, hasta contar con sectores específicos de recepción para embarazadas - protocolo que reduce el contagio por bacterias hospitalarias -. El carácter indefinido de la expresión "un montón de todo" denota que, para ella, estas cosas son excepcionales: no las tenía contempladas como un derecho.

En este segundo relato, el movimiento de cruzar fronteras está orientado por reflexiones sobre el mejor cuidado, y sólo muy secundariamente, por cálculos de rentabilidad económica (sobre el precio de estos servicios). Esta aseveración desafía un postulado central de la teoría neoclásica de las migraciones, que imputa la decisión de los sujetos sobre sus movilidades como anclada a cómputos racionales, sobre beneficios estrictamente económicos entre espacios nacionales (Kearney, 1986). Finalmente, Amarena interpreta que la atención prenatal en Puerto Iguazú constituía un "descuido" hacia las mujeres, pues dada la sobrecarga de los médicos y el incumplimiento de los horarios de consulta, ellas tenían que esperar varias horas para ser atendidas, lo que les dificultaba mantener sus empleos. Así, además de medir constantemente los cuidados, 
de un lado y otro de la frontera, el "cuidadómetro" se mueve tomando en cuenta la conciliación de actividades productivas y reproductivas.

En tercer lugar, Amarena explica que su manejo del portugués - debido al trabajo en el Duty Free -, le permitió comunicarse mejor con los/las médicos/as en Brasil. Y que no habría discriminación ni malos tratos a los/las argentinos/as, en la atención y servicios brasileños. Aquí, la posibilidad de cruzar la frontera para atenderse está conectada con un capital cultural que responde a su inserción laboral específica. Fueron los conocimientos lingüísticos exigidos para su inserción laboral los que le permitieron concebir estrategias transfronterizas de atención sanitaria.

Dicha posibilidad está, asimismo, potenciada por el hecho de que la disputa identitaria entre brasileños y argentinos parecía no estar vigente en la atención sanitaria o en el aspecto comercial. Amarena, como vendedora, se especializaba para "atender ejemplarmente" a los brasileños; a su vez, los brasileños atendían a las argentinas - como ella - "sin marcar diferencias". Cuando el asunto son los mercados y los servicios, prima una visión de las relaciones que pone un "paréntesis" a los conflictos entre las identidades nacionales.

El relato de Bernadette nos conduce a otra dimensión del "cuidadómetro" y de las ausencias de los Estados en sus responsabilidades del cuidado. Ella nos contaba que se había agotado tras diez años de estar sometida a un sinfín de exámenes, que implicaban horas y horas de espera, en filas interminables: "yo me cansé de ir al médico. Descubrí que lo que necesito es amor de verdad".

En sus declaraciones, destaco tres elementos centrales. Primero, su constatación de que su exposición a prácticas reiteradas de desatención en la salud pública estaba relacionada con su condición de clase. Los pobres eran quienes estaban sometidos a las filas y esperas interminables por servicios que, cuando finalmente llegaban, no satisfacían ni sus expectativas mínimas, ni sus necesidades inmediatas. Segundo, esta marginación de los pobres estaría profundamente vinculada a su sometimiento a una temporalidad de la espera, que magnificaba el impacto de la precariedad de la atención sanitaria. Ya fuera porque el sostenimiento en el tiempo de la desatención de sus problemas de salud los agravaba; o porque la obligación de ir y esperar, una y otra vez, de hacer varios trámites e insistir por tratamientos y atenciones sin respuestas también enferma ("de los nervios", decía). En tercer lugar, Bernadette constataba que la baja eficiencia de los médicos en la diagnosis y tratamiento de los enfermos se debía a su poca preparación como cuidadores: "ellos no saben cuidar". Según nos aseveró, ellos no sabían escuchar al enfermo, atenderlo en sus necesidades, computarlas y responder desde la empatía. Siguiendo con su explicación, concluyó que los médicos no sabían cuidar porque el tipo de cuidado que ella necesitaba - el "amor verdadero" - implica un tipo una empatía profunda, que supone una atención integral al destinatario del cuidado.

Esto remite a Wacquant (2010) y sus reflexiones sobre cómo el neoliberalismo genera modelos institucionalizados de castigo que reproducen la pobreza, a través de torturar procedimentalmente a quienes se encuentran en esta situación social, generando una ritualización de la exclusión. Como observaron Jelin y Vila (2018 [1987]) en otros contextos, esta ritualización está dada por el sometimiento a las filas, a las esperas para acceder a un derecho tan básico como la atención sanitaria. ${ }^{21}$

Pero Bernadette no solamente analizaba con total lucidez sus límites y posibilidades en este contexto, sino que, además, había producido una solución alternativa a sus demandas de "amor de verdad". Paseándose por las diferentes sedes de la IURD, observó que los pastores ofrecían medidas diferentes de este "amor" a sus fieles. Tras analizarlos, eligió el templo donde se sentía mejor cuidada. Esto implicaba desplazarse cruzando toda la ciudad desde su barrio al templo elegido; pero ella estaba dispuesta a hacerlo.

21 El estudio de Jelin y Vila (2018 [1987]) versa sobre las periferias urbanas pobres de Buenos Aires en los 1980s. Los autores constataron, entre otras cosas, que la vida en los barrios del conurbano empujaba las personas a hacerse con horas y más horas de espera para acceder a servicios básicos. Así, la mediación entre los sujetos y el goce de sus derechos estaría dada por el castigo de esperar. Filas interminables eran, entonces, el paisaje cotidiano de la experiencia de la pobreza, de los periplos que se extendían entre diversas oficinas y reparticiones gubernamentales (de servicios de salud, de escuelas públicas, etc.). 
El pastor del templo elegido, a su vez, se daba cuenta de esta demanda, necesidad y deseo de cuidados por parte de sus fieles (Bernadette y Alicia nos contaron que las mujeres son mayoría en las congregaciones de la IURD). Muchas de ellas pertenecen, precisamente, a sectores sociales vulnerables y, por lo general, están sobrecargadas con los cuidados de sus propias familias. A la vez, su inserción productiva gira en torno a los servicios domésticos en casas de terceros. Son mujeres que cuidan sin ser cuidadas. Atento a estos detalles, el pastor se disponía a recibirlas y a entregar formas multidimensionales de cuidado: espiritual (rezar para exorcizar los espíritus que provocan la enfermedad), emocional (mirar a los ojos, llamar por el nombre, indagar sobre el estado de salud), y comunitario (organizar a los fieles del templo, formando una red de cuidados, para que entre todos acompañaran los que necesitan, estando pendientes de ayudarlos en sus requerimientos).

En este último sentido del cuidado, el pastor usa su autoridad espiritual para organizar un intercambio de atenciones que se hacen entre las hermanas bajo su coordinación. Bernadette relató que las mujeres se sienten protegidas y cuidadas por la "comunidad". Con mucha habilidad, el pastor había creado un sistema comunitario de cuidados para un grupo social específico - las mujeres pobres - que carece de cuidados en otros ámbitos sociales. No obstante, Bernadette sabía claramente que esta cadena del cuidado - este "amor de verdad" - tenía una dimensión instrumental: los pastores esperan que ellas les otorguen su diezmo y su voto a cambio. El cuidado aparece, entonces, como un sistema de prestaciones totales, como una reciprocidad (Comas, 2017). Pero una reciprocidad instrumentalizada.

Entendiendo su situacionalidad en esta cadena, Bernadette estableció su propia agencia, eligiendo, entre los pastores disponibles, aquél que la cuidaba según sus necesidades. Ella es agente de esta elección: podría no frecuentar la IURD, o concurrir al templo de la congregación más cerca de su casa. Es suya la decisión de entregar su recurso económico - y su recurso político, el voto - al pastor que mejor la cuida. En esta decisión vemos operar, una vez más, el cuidadómetro. Las medidas del cuidado aparecen como un instrumento definidor del uso de los recursos económicos y políticos de que dispone Bernadette.

En conjunto, estas historias permiten establecer que las mujeres trazan circuitos de movilidad que están pensados como estrategias para responder a la sobrecarga de cuidados. Así, ellas establecen su relación con el territorio transfronterizo, calculando cuánto cuidado pueden recibir de un lado $\mathrm{u}$ otro de la frontera, $\mathrm{y}$ cómo pueden maximizar sus esfuerzos para cuidar, también, a terceros. Este cálculo las impulsa a establecer vinculaciones particulares con las tres ciudades que componen la Triple Frontera del Paraná, a la vez que configura un circuito transfronterizo del cuidado.

Sumisión: 17/06/2020

Aceptación: 31/10/2020

Revisión: Federico Lavezzo 


\section{Referencias bibliográficas}

ALBUQUERQUE, José Lindomar. 2008. "Fronteiras e identidades em movimento: fluxos migratórios e disputa de poder na fronteira Paraguay-Brasil". Cadernos Ceru, 19(1): 49-63.

ALBUQUERQUE, José Lindomar. 2012. "Limites e paradoxos da cidadania no território fronteiriço:

$O$ atendimento dos brasiguaios no sistema público de saúde em Foz do Iguaçu

(Brasil)". Geopolítica(s), 3(2): 185-205.

ALTHUSSER, Louis. 1988. Ideología y aparatos ideológicos del Estado. Buenos Aires: Nueva Visión.

ÁLVAREZ, Roberto. 1995."The Mexican-US border. The Making of an Anthropology of Borderlands". Annual Review of Anthropology, 24: 447-470.

ANZALDÚA, Gloria. 1987. Borderlands - La frontera. San Francisco: Aunt Lute.

ARANDA, Elizabeth. 2003. "Global Care Work and Gendered Constraints: The Case of Puerto Rican Transmigrants". Gender and Society, 17(4): 609-626.

ARRIOLA, Elvia. 2006. "Accountability for murder in the maquiladoras: linking corporate indifference to gender violence at the US-Mexico border". Seattle J. Soc. Just., 5(2): 603-619.

BARVINSK, Georgina. 2014. "La trata de mujeres con fines de explotación sexual en la región de la triple frontera" . Revista Latinoamericana de estudios de seguridad, 14: 68-78.

BEAUVOIR, Simone. 2018 [1949]. El segundo sexo. Buenos Aires: Lumen.

BOURDIEU, Pierre. 2011. Las estrategias de la reproducción social. Buenos Aires: Siglo XXI.

BRYCESON, Deborah \& VUORELA, Ulla. 2002. "Transnational Families in the 21st Century”. In: (eds.),

The Transnational Family: New European Frontiers and Global Networks. Oxford: Berg Publishers. pp. 3-30.

CARDIN, Eric. 2012. "Trabalho e práticas de contrabando na fronteira do Brasil com o Paraguay". Revista Geopolíticas, 3(2): 207-234.

COMAS, Dolors. 2017. "El don y la reciprocidad tienen género: las bases morales de los cuidados". Quaderns-e de l'Institut Català d'Antropologia, 22(2): 17-32.

COSTA, Thomaz \& SCHULMEISTER, Gastón. 2007. "The puzzle of the Iguazu tri-border area: Many questions and few answers regarding organised crime and terrorism links". Global Crime, 8(1): 26-39.

CURY, Mauro \& FRAGA, Nilson. 2013. “Conurbação Transfronteiriça e o Turismo na Tríplice Fronteira: Foz Do Iguaçu, Ciudad Del Este e Puerto Iguazú”. Rosa dos Ventos, 5(3): 46o-475.

DACHARY, Alfredo \& ARNAIZ, Stella. 2012. "Región fronteriza de Argentina y Brasil: asimetrías y potencialidades". Revista Desenvolvimento Regional em Debate, 2(1): 204-231.

DALY, Mary \& LEWIS, Jane. 2000. "The concept of social care and the analysis of contemporary welfare states". British Journal of Sociology, 51(2): 281-298.

FERGUSON, Susan. 2008. "Canadian contributions to social reproduction feminism, race and embodied labor". Race, Gender and Class, 15(1-2): 42-57.

FOGEL, Ramón. 2008. "La región de la triple frontera: territorios de integración y desintegración". Sociologías, 20: 270-290.

GARDUÑO, Everardo. 2003. "Antropología de la frontera, la migración y los procesos transaccionales". Frontera Norte, 15(30): 65-89.

GIMÉNEZ, Verónica. 2011. "La "triple frontera” y sus representaciones: Políticos y funcionarios piensan la frontera". Frontera Norte, 23(46): 7-34.

GIOVANELLA, Ligia. 2007. Saúde nas fronteiras: estudo do acesso aos serviços de saúde nas cidades de fronteira com países do MERCOSUL. Rio de Janeiro: ENSP/ Fiocruz.

GLENN, Evelyn. 2010. Forced to care: Coercion and caregiving in America. Cambridge: Harvard University Press. GONZÁLVEZ, Herminia. 2016. "Los cuidados en la migración transnacional. Una categoría de análisis social y política”. Sur. Revista Internacional de Derechos Humanos, 24: 43-52. 
GONZÁLVEZ, Herminia; GUIZARDI, Menara \& RAMÍREZ, Alfonsina; CANO, Catalina. 2019. "El club como trinchera. Una etnografía sobre cuidados comunitarios entre mujeres mayores en Independencia (Chile)". Revista de Antropología Social, 28(1): 137-166.

GRIMSON, Alejandro. 2002. Los flujos de la fronterización: Una etnografía histórica de la nacionalidad en Paso de los Libres (Argentina) y Uruguayana (Brasil). Tesis de doctorado. Departamento de Antropología, Universidad Nacional de Brasília, Brasil.

GRIMSON, Alejandro. 2011. "Doce equívocos sobre las migraciones”. Revista Nueva Sociedad, 233: 34-43. GRIMSON, Alejandro. 2012. Mitomanías argentinas. Cómo hablamos de nosotros mismos. Buenos Aires: Siglo XXI.

GUBER, Rosana. 2001. La etnografía: método, campo y reflexividad. Buenos Aires: Editorial Norma. GUIZARDI, Menara; GONZÁLEZ, Herminia \& STEFONI, Carolina. 2018. "De feminismos y movilidades. Debates críticos sobre migraciones y género en América Latina (1980-2018)” . Rumbos TS, 18: 37-66. GUIZARDI, Menara; VALDEBENITO, Felipe; LÓPEZ, Eleonora \& NAZAL, Esteban. 2019. Des/venturas de la frontera. Una etnografía sobre las mujeres peruanas entre Chile y Perú. Santiago: UAH.

HERRERA, Gioconda. 2012. "Género y migración internacional en la experiencia latinoamericana. De la visibilización del campo a una presencia selectiva”. Política y sociedad, 49(1): 35-46.

HOCHSCHILD, Arlie. 2001. Las cadenas globales de afecto y asistencia y la plusvalía emocional. In: A. Giddens \& W. Hutton (eds.), El límite: la vida en el capitalismo global. Barcelona: Tusquets. pp. 187-209. HOSPITAL MINISTRO COSTA CAVALCANTI [HMCC]. 2019. "Um hospital criado para os operários e que hoje trabalha para TODOS”) (online). Disponible en: http://www.hmcc.com.br/institucional.php. Consultado: 30.08.2019.

INSTITUTO BRASILEIRO DE ESTATÍSTICAS E GEOGRAFIA [IBGE]. 2010. Censo Demográfico 2010: Características gerais da população, religião e pessoas com deficiência. Brasilia: IBGE. Disponible en: https:/| ww2.ibge.gov.br/home/estatistica/populacao/censo2010/caracteristicas_religiao_deficiencia/default_ caracteristicas_religiao_deficiencia.shtm. Consultado: 22.08.2019.

JELIN, Elizabeth \& VILA, Pablo. 2018 [1987]. Podría ser yo. Los sectores populares y urbanos en imagen y palabra. Buenos Aires: IDES.

KEARNEY, Michael. 1986. "From the invisible hand to visible feet: anthropological studies of migration and development". Annual Review of Anthropology, 15(1): 331-361.

LAMAS, Marta. 1986. "La antropología feminista y la categoría 'género". Nueva antropología, 8(30): 173-198.

LASLETT, Barbara \& BRENNER, Johanna. 1989. "Gender and social reproduction: Historical perspectivas”. Annual Review of Sociology, 15(1): 381-404.

LIMA, Sancléya \& CARDIN, Eric. 2019. "As representações de mulheres na faixa de fronteira entre Brasil e Paraguai”. Revista Caribeña de Ciencias Sociales. Disponible en: https://www.eumed.net/rev/caribe/2019/05/ representacoes-mulheres.html. Consultado: 24.06.2019.

LINS RIBEIRO, Gustavo. 1999. La Represa de Yacyretá. Capitalismo Transnacional y Política Hidroenergética en la Argentina. Posadas: Editorial Universitaria.

LUGO, Alejandro. 1990. "Cultural production and reproduction in Ciudad Juárez, México: Tropes at play among maquiladora workers". Cultural Anthropology, 5(2): 173-196.

LYNN, Josefina. 2008. “La Triple Frontera y la amenaza terrorista ¿realidad o mito?” In: F. Rivera Vélez (ed.), Seguridad multidimensional en América Latina. Quito: FLACSO. pp. 57-80.

MACEIRA, Daniel. 2006. Descentralización y equidad en el Sistema de Salud Argentino. Buenos Aires: La Colmena.

MACHADO, María \& BURITY, Joanildo. 2014. "A ascensão política dos pentecostais no Brasil na avaliação de líderes religiosos”. Dados, 57(3): 601-631. 
MATTINGLY, Doreen. 2001. "The home and the world: domestic service and international networks of caring labor". Annals of the Association of American Geographers, 91(2): 370-386.

MOLINA, Frieda. 1985. "The social impacts of the maquiladora industry on mexican border towns". Berkeley Planning Journal, 2(1): 30-40.

MONÁRREZ, Julia. 2013. Trama de una injusticia; feminicidio sexual sistémico en Ciudad Juárez.

Ciudad Juárez: Colef.

MORALES, María \& BEJARANO, Cynthia. 2009. "Transnational sexual and gendered violence an application of border sexual conquest at a México-US border". Global Networks, 9(3): 420-439.

ORGANIZACIÓN INTERNACIONAL DEL TRABAJO [OIT]. 2002. Políticas sociales y ofertas institucionales para la confrontación de la explotación sexual comercial de niñas, niños y adolescentes en la frontera Paraguay-Brasil (Ciudad del Este). Lima: OIT.

ORO, Ari. 2004. "A presença religiosa brasileira no exterior: o caso da Igreja Universal do Reino de Deus”. Estudos Avançados, 18(52): 139-155.

PISANI, Michael \& YOSKOWITZ, David. 2002. "The maid trade: Cross-border work in South Texas". Social Science Quarterly, 83(2): 568-579.

PROFIT, Alena. 2015. El hombre soy yo. Dinâmicas familiares no contexto da imigração paraguaia no Brasil. Tesis de maestría. Universidad de Brasilia, Brasil.

RABOSSI, Fernando. 2004. Nas ruas de Ciudad del Este: vidas e vendas num mercado de fronteira. Tesis de Doctorado. PPGAS/Museu Nacional/ Universidade Federal do Rio de Janeiro, Brasil.

RAPP, Rayna. 1975. Toward an anthropology of women. Harvard: Monthly Review Press.

REBER, Vera. 1988. “The Demographics of Paraguay: A Reinterpretation of the Great War, 1864-70”. Hispanic American Historical Review, 68(2): 289-319.

RENOLDI, Brígida. 2013. "Fronteras que caminan: relaciones de movilidad en un límite trinacional”. Revista Transporte y Territorio, 9:123-140.

RENOLDI, Brígida. 2014. "Conceptos que hacen el Estado: crimen organizado y prácticas policiales en la Triple Frontera”. Actas del Seminario Anual del Programa de Estudios sobre Saberes de Estado y Elites Estatales. Buenos Aires, Argentina. Mimeo.

RIBEIRO, Verá \& GEUSINA, Maria. 2008. "Brasiguaios: a dupla desigualdade na região da frontera". Pleiade, 2(2): 31-46.

ROSALDO, Michelle \& LAMPHERE, Louise. 1974. Woman, Culture, and Society. Stanford: Stanford University Press.

SASSEN, Saskia. 2003. Contrageografías de la globalización. Género y ciudadanía en los circuitos transfronterizos. Madrid: Traficante de Sueños.

SAUSI, José \& ODDONE, Nahuel. 2010. “Cooperación e integración transfronteriza en el Mercosur: el caso de la Triple Frontera Argentina-Brasil-Paraguay”. In: L. Maira (ed.), La política internacional subnacional en América Latina. Buenos Aires: Del Zorzal. pp. 209-258.

SEAMAN, Brian. 2012. "Cry for me Argentina. The commercial sexual explotation of children in south América”. Law Now. Disponible en: https:|/www.lawnow.org/commercial-sexual-exploitation-ofchildren-in-south-america/. Consultado: 01.10.2019.

SIQUEIRA, Domingos. 2015. "105 bandeiras para 8 milhões". Correio do Povo, s/p. Disponible en: https:/|www. correiodopovo.com.br/not\%C3\%ADcias/geral/artigo-105-bandeiras-para-8-milh\%C3\%B5es-1.187055. Consultado: 22.08.2019.

SOUCHAUD, Sylvain. 2011. "A visão do Paraguai no Brasil”. Contexto Internacional, 33(1): 131-153.

STEPHEN, Lynn. 2012. "Conceptualizing Transborder Communities". In: M. Rosenblum; D. Tichenor (eds.), Oxford Handbook of the Politics of the International Migration. Oxford: Oxford University Press. pp. 456-477. 
VITERI, María; CEJA, Ireri \& YÉPEZ, Cristina. 2017. Corpografías: género y fronteras en América Latina. Quito: FLACSO.

WACQUANT, Loïc. 2010. Castigar a los pobres. El gobierno neoliberal de la inseguridad social. Barcelona: Gedisa. WOO, Ofelia. 2004. “Abuso y violencia a las mujeres migrantes”. In: T. Fernández (ed.), Violencia contra la mujer en México. Ciudad de México: Comisión Nacional de los Derechos Humanos. pp. 71-84.

ZSÖGÖN, María. 2013. "Explotación sexual comercial infantil en la triple frontera entre Argentina, Brasil y Paraguay”. Ideação, 15(2): 110-128.

\author{
Menara Guizardi \\ Investigadora postdoctoral del Consejo Nacional de Investigaciones Científicas y Técnicas \\ (CONICET/IDAES/UNSAM), Buenos Aires, Argentina \\ https://orcid.org/o0oo-0003-2670-9360 \\ E-mail: menaraguizardi@yahoo.com.br
}

